\title{
Los barrios parque $y$ de fin de semana en el mapa de la expansión metropolitana. Buenos Aires, 1910-1950
}

Ana Gómez. Universidad Nacional de La Plata (UnLP), Buenos Aires, Argentina.

RESUMEN | En el marco del interés que suscitan los recientes procesos de suburbanización protagonizados por los sectores medios y medios altos, surge la necesidad de identificar núcleos y emprendimientos suburbanos surgidos durante la primera mitad del siglo xx, pensándolos como antecedentes de los fenómenos actuales y partícipes en la formación del territorio metropolitano de Buenos Aires. Desde una perspectiva histórica, nos preguntamos cómo contribuyeron los barrios de fin de semana a producir una nueva configuración del Gran Buenos Aires (GBA). Del corpus de casos seleccionados surge que, más allá de los matices y del rol limitado que en términos materiales tuvieron los barrios de fin de semana en la expansión metropolitana, su relevancia radicó en su capacidad para consolidar los ejes de crecimiento y configurar en su irradiación formas particulares de la expansión.

PALABRAS CLAVE | expansión urbana, áreas metropolitanas, historia urbana.

ABSTRACT | Between 1910 and 1950, the Buenos Aires Metropolitan Area experienced a particular type of urban sprawl based on the growth in the construction of garden suburbs and weekend housing developments. Initially associated with the upper and middle classes, these type of suburbs would become available to other social groups throughout the same period. In this context, it is sought to identify the role played by these suburban nuclei in the construction of the metropolitan area. More specifically, this work seeks to shed light on how such areas contributed to the creation of the new structure of Greater Buenos Aires. Beyond the differential and current role such areas have played in material terms, their importance lays in their power to consolidate axes of growth, and to configure particular forms of urban sprawl in their surrounding areas.

KEY WORDS | urban sprawl, metropolitan areas, urban history. 


\section{Introducción}

En las últimas dos décadas, la Región Metropolitana de Buenos Aires ha experimentado un nuevo proceso de expansión. Solamente entre 1996 y 2000 se concretaron 160 emprendimientos de urbanizaciones cerradas destinadas a usos residenciales de los sectores medios y altos, en un área de 30.000 hectáreas, vale decir, una vez y media la superficie de la Capital Federal. La caída en la inversión pública -que contribuyó al deterioro de las áreas centrales- y la construcción de nuevas vías rápidas de acceso a los grandes centros urbanos propiciaron la formación de urbanizaciones privadas que se localizaron cercanas a un cruce de vías rápidas de circulación o a los accesos de las autopistas, determinando el asentamiento de importantes sectores de la población en áreas periurbanas de la ciudad. "La tranquilidad del campo", "el contacto con la naturaleza" y la posibilidad de "disfrutar de la familia" y de los "deportes al aire libre", junto a los crecientes problemas de inseguridad asociados a las grandes ciudades, fueron algunas de las fórmulas esgrimidas tanto en las ofertas de los agentes inmobiliarios como en las demandas de los habitantes a la hora de explicar el traslado de la residencia por fuera del área urbana. Este fenómeno, de larga data en otros países de América Latina, en Argentina no fue privativo de Buenos Aires, pues, en menor escala, se fue experimentando en otras capitales de provincia: Rosario, Córdoba, Mendoza y La Plata.

Si bien se trata de un fenómeno de nueva generación, la formación de núcleos extraurbanos de usos exclusivamente residenciales, favorecidos por las prácticas recreativo-deportivas y la unión familiar en un entorno "natural", no es del todo novedosa en la expansión territorial del Gran Buenos Aires (GBA). Aunque es conocido el perfil predominantemente popular que caracterizó el crecimiento metropolitano en Latinoamérica, no es menos cierto que, en el caso de Buenos Aires, muchas de las lógicas de ocupación territorial, de las imágenes y de los valores que guían actualmente el proceso de suburbanización de los sectores medios y medios-altos, ya se habían hecho presentes en otros escenarios y signaron los procesos de expansión residencial que ha experimentado la ciudad (Ballent, 1998). Desde esta perspectiva, se asume el abordaje de una temporalidad particular, la del artefacto urbano, en el que el "pasado" permanece "presente" a través de las huellas materiales que inciden activamente en la vida cotidiana.

En el marco del renovado interés que suscitan los recientes procesos de suburbanización, este trabajo se propone identificar los núcleos y emprendimientos suburbanos capaces de ser pensados como antecedentes de los fenómenos actuales. Se considera aquellos que, asociados inicialmente a formas de habitar modernizadoras, vincularon residencia no permanente, actividades recreativas y deportivas en un entorno "natural", a fin de establecer su participación en la formación del territorio metropolitano.

Desde la bibliografía, a pesar del nutrido grupo de autores dedicado a analizar los procesos de suburbanización iniciados a fines de la década de los ochenta (Svampa, 2001; Szajnberg, 2001; Vidal-Koppmann, 2000), los estudios que tanto en el contexto local como latinoamericano han analizado la primera mitad del siglo xx han avanzado hipótesis tendientes a remarcar el carácter popular de la expansión (Morse, 1969; Romero, 1976; Castells, 1973; Sargent, 1974; Clichevsky, 1975; Torres, 1975, 1978). 
Más allá de estas caracterizaciones generales, es posible reconocer procesos particulares que contribuyeron a la generación del GBA. En efecto, se observa que a partir de 1910 se asistió en el área metropolitana al desarrollo de un tipo particular de suburbio moderno, articulado en torno a la residencia de verano o de fin de semana y en combinación con la oferta deportiva o paisajística de un área, destinado a la habitación de sectores medios y medios-altos. Estos procesos, asentados sobre la tradición de las clases altas de pasar las temporadas cálidas en los pueblos suburbanos, se ampliarían a inicios del siglo xx, contribuyendo a instalar y difundir tempranamente en nuestro país prácticas modernas asociadas al veraneo, el turismo, los deportes o el habitar suburbano. Este fenómeno reducido, estructurado inicialmente alrededor de algunas estaciones ferroviarias, se extendería a lo largo de los años veinte y treinta, junto con la ampliación en la oferta de loteos en zonas suburbanas de reciente accesibilidad, siguiendo una lógica de ocupación territorial nueva, hegemonizada por el tendido de la red vial.

Queremos plantear, entonces, que es posible reconocer un proceso de larga duración, que se habría iniciado hacia 1910 y concluiría alrededor de 1950, en el cual se asistió a la formación y consolidación de núcleos suburbanos surgidos de operaciones inmobiliarias que se plantearon como predominantemente residenciales de fin de semana y contribuyeron a imprimir una matriz diferente de aquella de carácter masivo que definió globalmente la bibliografía.

Ahora bien, ¿cómo incidieron los barrios parque en la construcción de la nueva periferia?

Para responder a esta pregunta, el núcleo central de este análisis se funda en un corpus de ochenta y dos casos relevados en el Departamento de Investigación Histórica Cartográfica de la Dirección de Geodesia del Ministerio de Obras Públicas (MOP) de la Provincia de Buenos Aires. Los datos destacados se presentan en un cuadro síntesis incorporado al final del artículo, el cual permite en esta oportunidad tener acceso a la información resumida, a la vez que facilita el análisis descriptivocomparativo de las urbanizaciones que a continuación se presenta. Trataremos de dar cuenta de las principales características del proceso expansivo, respondiendo a las preguntas sobre quiénes fueron sus protagonistas, cuáles fueron los usos predominantes que allí se localizaron, qué diferencias había entre los sectores de la expansión. En segundo lugar, abordaremos el análisis de las áreas de expansión en coincidencia con los dos períodos que definimos como de primacía de la red vial (1910-1935) y posteriormente de la red de tránsito automotor (1935-1950). En cada caso, se tratará de comprender las dimensiones del fenómeno e identificar las relaciones que se establecen entre las urbanizaciones, los elementos urbanos preexistentes, y los ejes de crecimiento en relación con su localización y su propia organización interna. Se busca reconocer las transformaciones territoriales que la incorporación de núcleos suburbanos acarrea en cada momento y en relación a cada uno de los tres ejes principales de crecimiento.

Por último, vale aclarar que el propósito ha sido plasmar un panorama amplio. A través de la clasificación de una cantidad de casos variados, se buscó elaborar una síntesis clara de los principales modos de apropiación del suburbio vinculados a los procesos de formación de núcleos de fin de semana. De ninguna manera se ha 
buscado disimular ni, por el contrario, otorgar excesivo protagonismo a aquellos emprendimientos o casos particulares que se despegan de las lógicas más generales, y que se irán señalando, cuando sea oportuno, a lo largo del texto.

\section{El proceso de la expansión}

En el año 1900, la ciudad de Buenos Aires alcanzaba el millón de habitantes, mientras en su periferia se distinguían algunas industrias rodeadas de núcleos urbanos obreros y algunas poblaciones que habían surgido en torno a antiguas estancias o pueblos coloniales. Para mediados de los ańos treinta, la ciudad y el cinturón formado por los partidos que la rodeaban ya superaban ampliamente los cuatro millones de habitantes. Buenos Aires ingresaba al siglo xx como una de las ciudades más grandes del mundo y la más importante de Latinoamérica. Ciudades como México, Río de Janeiro y San Pablo alcanzaron el millón de habitantes solo para 1930. La Habana, Lima, Santiago, Bogotá, Caracas y Montevideo llegaron a esa cifra después de 1950. Para esta fecha, las primeras ciudades en experimentar procesos de expansión y metropolización ya presentaban fenómenos de conurbación (Torres \& Schteingart, 1971).

En Buenos Aires, los procesos de conurbación se iniciaron durante las primeras décadas del siglo $\mathrm{xx}$, cuando se experimentó un período de rápido crecimiento poblacional en los partidos aledaños a la Capital Federal. Acompañando la extensión de las redes ferroviarias, proliferaban los loteos y la formación de pueblos, aunque gran parte del crecimiento verificado se debió a una densificación de los núcleos que existían con anterioridad, generada por la paulatina emergencia de loteos yuxtapuestos a aglomeraciones surgidas hacia fines del siglo XIX.

Con la llegada del ferrocarril, los tradicionales pueblos de veraneo de la elite, con sus quintas del siglo XIX -Adrogué, Lomas y Temperley al sur; San Fernando, San Isidro y Tigre al norte; y, más tímidamente, Morón o Hurlingham hacia el oeste- comenzaron a rodearse de chalets $^{1}$, a la vez que se incorporaban clubes e instalaciones deportivas que ponían de manifiesto el proceso de modernización social y cultural que estaba teniendo lugar. Si bien en este momento la formación de núcleos de veraneo y de fin de semana era prerrogativa exclusiva de las clases altas, se percibía que lentamente comenzaban a perder su carácter aristocrático (Ballent, 1998; Losada, 2008).

El rápido desarrollo del mercado inmobiliario, impulsado por lo que se vivía como un proceso de expansión inagotable de la ciudad y de los medios técnicos que la propiciaban, hacía posible la revalorización de antiguos pueblos y el completamiento de manzanas y vacíos intersticiales en áreas ya pobladas. A la vez que los

1 La denominación "chalet" se utilizó entre el público masivo en Argentina para designar toda construcción individual pintoresca, de cubierta inclinada, en general de planta compacta, que puede desarrollarse en uno o varios niveles. Fue originalmente considerado un tipo de residencia suburbana, o casa de veraneo, aunque en la Argentina, a partir de fines de los ańos treinta, su uso se extendió en muchos casos a las ciudades. El término, de origen francés, da cuenta de la importancia de las referencias de ese origen para las arquitecturas pintorescas en el medio local (Ballent, 2004). 
procesos de suburbanización de los sectores medios-altos y altos convertían a los pueblos de veraneo -especialmente sobre la franja costera al norte de la Capital- en sitios de uso cada vez más frecuente, podían registrarse nuevos emprendimientos que se sumaban a esta tendencia de crecimiento.

En este punto, es necesario aclarar que para comienzos del siglo $\mathrm{xx}$, las tierras sobre las que se perpetraba la expansión de Buenos Aires estaban mayoritariamente en manos de agentes privados, quienes decidían lotearlas ante la llegada del ferrocarril, del trazado de un nuevo camino o de cualquier otra señal que prometiera su valorización. Se generó así una urbanización de origen "espontáneo" (en el sentido de que no deviene de los instrumentos convencionales de la planificación urbanística), y cuyo desarrollo en el tiempo se organizó de acuerdo con una primera fase de parcelación o loteo (división del suelo), un segundo momento de ocupación y generación de la edificación, y un último estadio de instalación de infraestructura (urbanización de calles y provisión de redes de servicios).

Hasta la década de 1960, el Estado no exigió la incorporación de infraestructura de servicios para la aprobación de los loteos, lo cual mantuvo los valores financieros de la tierra en un nivel relativamente bajo, facilitando el acceso a la propiedad de amplios sectores de la población ${ }^{2}$. Esta situación, junto a la popularización del uso del colectivo -más económico que el ferrocarril y capaz de llegar a las zonas intersticiales donde la tierra era más barata-, dio lugar al conocido auge que los loteos y urbanizaciones económicas experimentaron en las áreas cercanas a la Capital. Sin embargo, la expansión también posibilitó otro tipo de loteo, el de quintas de fin de semana que prometían un descanso reparador, al alcance de una nueva clase media ${ }^{3}$. A lo largo de las rutas nacionales, a escasa distancia de las estaciones ferroviarias o adentrándose un poco por los caminos de tierra de las zonas intermedias, ya era posible acceder a esa "paz campestre" que se ofrecía en las promociones de los loteos (Chiozza, 1983). Una vez que el anillo de tierras periféricas más cercanas a la Capital mostraba señales de completamiento -principalmente en torno a las vías radiales de acceso a la Capital, lo cual ocurrió entre las décadas de 1930 y 1950-, nuevos territorios comenzaron a incorporarse a la urbanización. En estas nuevas áreas, algunas familias de los recientemente engrosados sectores medios comprarían un "terrenito barato", pensando en levantar de a poco la "casita de fin de semana".

En cuanto a su localización, un plano general donde se señala la ubicación de la totalidad de los loteos de fin de semana (Figuras la y 1b), pone en evidencia zonas de ocupación heterogéneas que obedecerían a dos patrones bien diferenciados en la

2 La ley provincial no 3487, de 1913, de Creación de Nuevos Centros de Población y Ampliación de Ejidos, estableció las reglamentaciones y los procedimientos para la presentación y aprobación de los trazados y algunos requisitos en relación con cuestiones morfológicas: se establecían anchos mínimos para calles y avenidas, de 15 y 20 metros respectivamente; se establecían los porcentajes de superficie que los propietarios debían ceder para uso público. En cambio, resultaban ausentes las referencias al posible destino, uso de las tierras y a la introducción de servicios. Recién en diciembre de 1968, el gobierno de la Provincia de Buenos Aires dictó el decreto no 14.381/68 exigiendo la incorporación de infraestructura de servicios básicos (desagües pluviales, energía eléctrica, pavimentos y red de agua potable) en las subdivisiones por realizarse. Esta última ley marcó el fin de los loteos económicos en la periferia.

3 Para un estudio clásico sobre clases sociales en Argentina, véase Germani (1942). 
ocupación del suburbio: el primero, definido por las lógicas de ocupación generadas por el ferrocarril; y el segundo, por la ampliación y extensión de carreteras. Globalmente, se puede considerar que estas dos lógicas se relacionan con dos períodos, que definimos, entre 1910 y 1935, como de primacía ferroviaria; y de 1935 a 1950, como de ampliación de las carreteras y uso del automóvil. Podemos decir-aunque de manera algo esquemática- que a lo largo de dichos períodos se asistió a la ocupación de la zona norte, primero, y noroeste y oeste, después. Puede verse, en primer lugar, que los núcleos de los nuevos loteos dibujan lo que, de manera general, se puede describir como un anillo que forma un cinturón alrededor de la Capital, alejado entre 20 y 40 kilómetros. Aparece así un primer límite, que adquiere mayor definición en la zona interior, dada por una sucesión de emprendimientos sobre la línea que se consolidaría como el Camino de Cintura (1941); y un límite externo más difuso, que solo se consolida en la porción norte-noroeste. Hacia el interior del anillo, los niveles de ocupación difieren, pasando de una mayor ocupación inicial en la zona norte a un crecimiento posterior del noroeste y oeste, donde se aglutina la mayor cantidad de nuevos parcelamientos.

\section{FIgURA I | Localización de los barrios parque y núcleos de fin de semana en el GBA y distancias a la Capital}

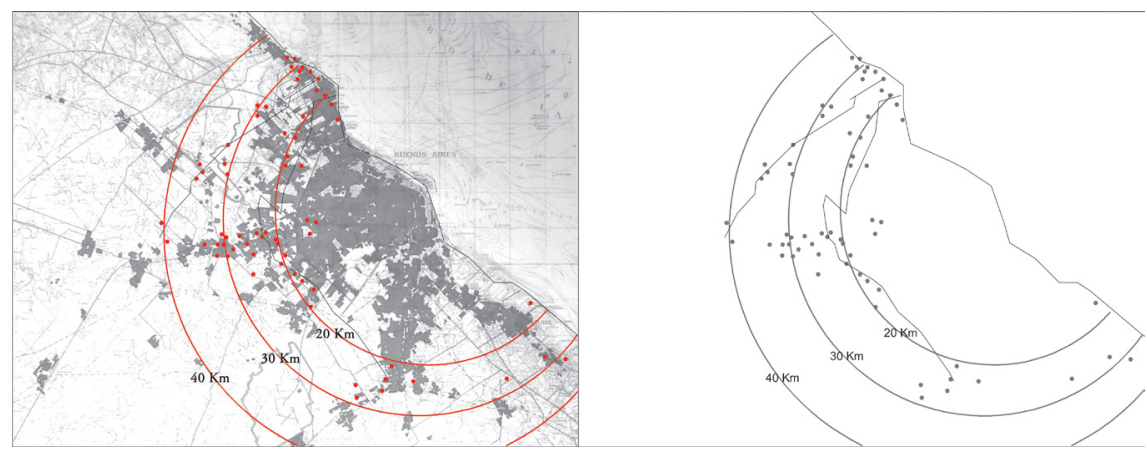

FUENTE ELABORACIÓN PROPIA SOBRE EL PLANO BASE DE RANDLE QUE SEÑALA LAS ÁREAS URBANIZADAS PARA I 948

Por último, si ponemos la lupa sobre el conjunto de los barrios parque que analizamos dentro del contexto de la expansión del GBA, el barrio parque aparece asociado predominantemente a la baja densidad generada por las dimensiones amplias de los lotes, más que al tipo de trazado que los contiené.

Casi en las dos terceras partes de los casos relevados pudimos ver que se ofrecían como quintas o como dobles lotes, que implicarían medidas superiores a los $600 \mathrm{~m}^{2}$. Además, en algunos casos singulares, se pusieron a la venta fracciones de entre 1.000 y $1.500 \mathrm{~m}^{2}$, susceptibles de ser subdivididas de acuerdo con el crecimiento y densificación que fuese adquiriendo la zona. Solo en la tercera parte de los casos encontramos tamańos de lotes pequeños (entre 300 y $500 \mathrm{~m}^{2}$ ), con medidas que generalmente toman la proporción de $10 \mathrm{~m}$ de frente y largos variables. En otras ciudades, como Mar del Plata, en este mismo periodo, Perla Bruno (1997) analiza que la imagen compartida y generalizada de "Mar del Plata ciudad jardín" se basa fundamentalmente en la profusión de parques públicos y jardines privados, en el tratamiento pintoresco de los 


\section{El ciclo 1910-1935}

\section{Un panorama...}

FIGURA 2 | Expansión del GBA para 1910

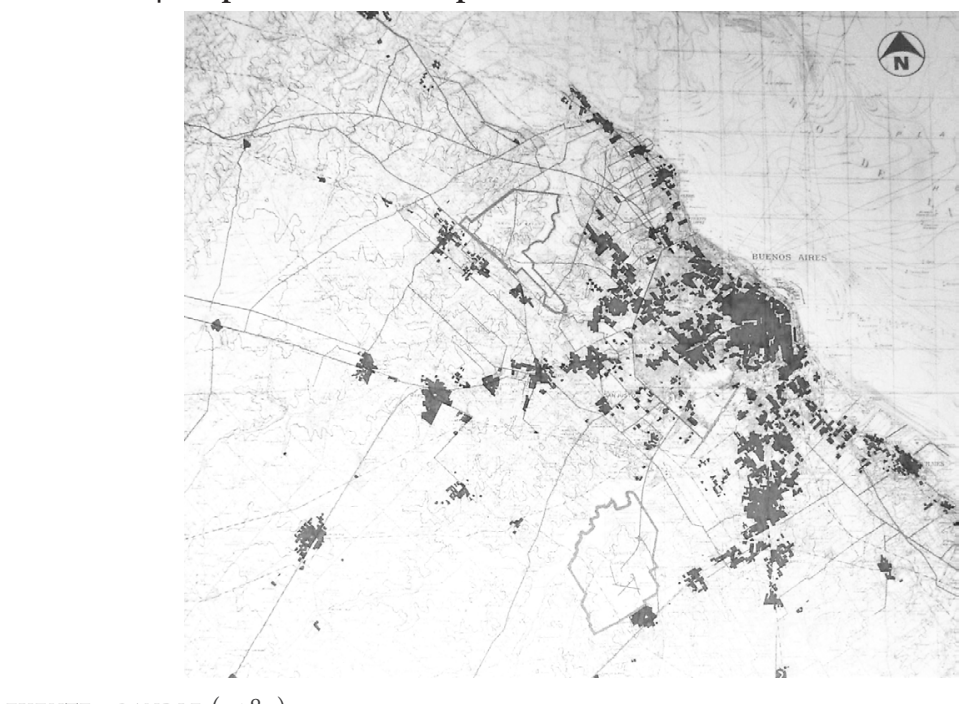

FUENTE RANDLE (1987)

En relación con la expansión, este primer momento, que puede caracterizarse como de suburbanización incipiente, reúne aproximadamente el 20\% del total del corpus que analizamos para todo el período. Salvo excepciones -como el Barrio Parque Manuel Obligado, en Almirante Brown, o el Barrio Parque Lavallol, en Lomas de Zamora-, la expansión urbana se da fundamentalmente en el sector norte del GBA y alrededor de algunos pueblos tradicionales del oeste, destinados a los llamados sectores acomodados de la sociedad. Es sabido que se trata de un período signado por la existencia del ferrocarril. Como ya adelantamos, a partir de su llegada, los tradicionales pueblos de veraneo de la elite iniciaban un proceso de transformación y modernización.

Un simple análisis sobre el mapa de la expansión (Figura 2) nos muestra la concentración residencial en torno a las estaciones del ferrocarril, que hasta aproximadamente la década de 1930 dejaría ver -exceptuando la zona sur- que cada estación y el conjunto de manzanas relativamente consolidadas que la rodeaban formaban núcleos en sí mismos, envueltos por una porción de campo que los separaba del núcleo siguiente. Asimismo, la lectura de los avisos publicitarios que acompañan los loteos que analizamos puede ser un indicio de la primacía de la red ferroviaria

\footnotetext{
detalles, la abundancia de aire y sol, sin considerar aspectos económicos, ni límites de densidad ni superficie, ni definición de las partes. Incluso una vez que se establece la primera Ordenanza de Barrios Parque en 1943, su vinculación con la idea de ciudad jardín es fundamentalmente estética, definida por una edificación retirada de la línea con jardines al frente.
} 
en los primeros años de la expansión: se observa que en las referencias geográficas se consigna, además de la distancia a la Capital, la distancia entre los terrenos en venta y la estación. Tal situación se revertirá en el segundo periodo que analizamos, cuando empiezan a tomar importancia las redes viales y rutas pavimentadas.

En este momento, entonces, el análisis de los emprendimientos muestra que en los primeros ańos de la expansión predominan dos tipos de formaciones: por una parte, aquellos loteos relacionados al ferrocarril que contribuyen a consolidar núcleos previos, muchos de ellos surgidos en el siglo XIX, como Morón o Adrogué; y por otra, las operaciones en torno a nuevas estaciones que van surgiendo en las zonas donde se presiente una mayor densificación y existen intereses concretos, generalmente inmobiliarios, que buscan favorecer la subdivisión del suelo y la creación de nuevos loteos 5 .

\section{FIgURA 3 | Plano del Barrio Parque Manuel Aguirre, circa 1914}

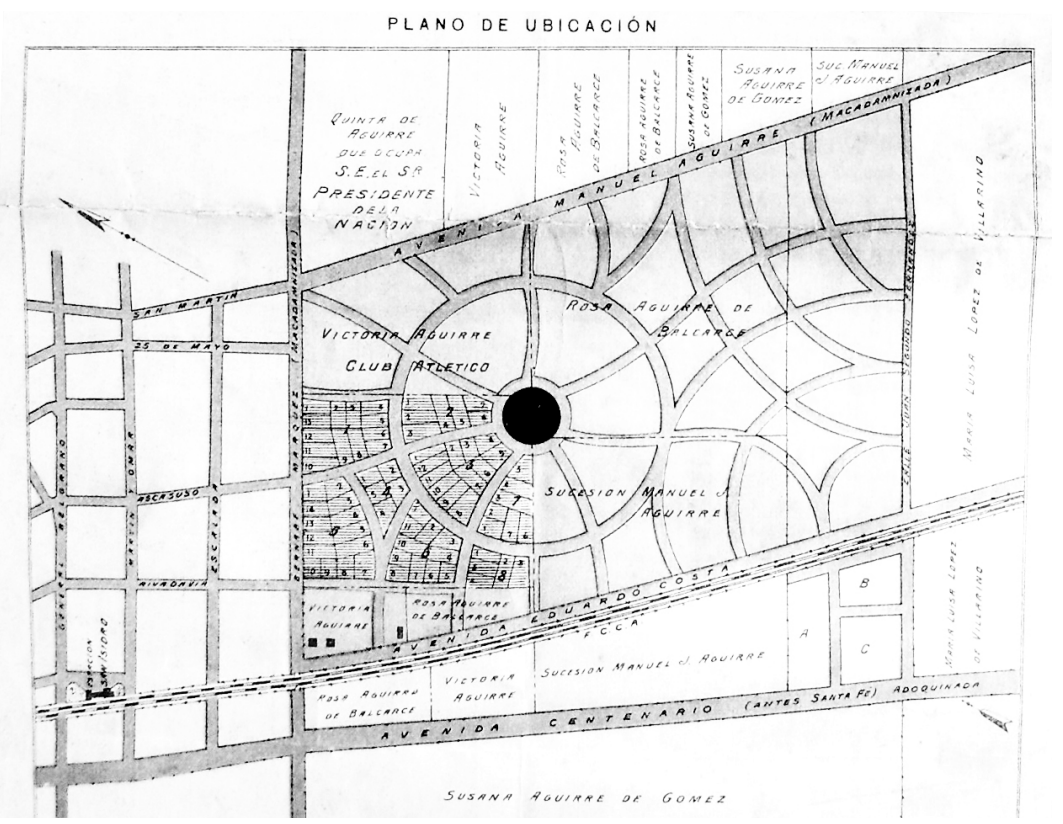

FUENTE PROMOCIÓN DE REMATE DE TIERRAS. CARPETA BARRIO PARQUE AGUIRRE, ARCHIVO Y MUSEO HISTÓRICO DE SAN ISIDRO.

$5 \longdiv { \text { Si recordamos lo que seńaló Charles Sargent (1974), la década de } 1 8 9 0 \text { representa el auge } }$ de la especulación "institucional", consistente en la venta por parte de los terratenientes de grandes extensiones a los empresarios de la especulación urbana, muchas veces antes de que se hiciera efectiva la inversión pública y privada en transporte y equipamiento. Recién luego de la recuperación de 1904, y una vez que se contaba con cierta infraestructura mínima, a la vez que se expandía la costumbre de pasar el verano en alguna quinta en las afueras de la ciudad, las tierras de las antiguas estancias - a veces en manos de inversores y otras por parte de las mismas familiascomenzaron a lotearse para dar lugar a la formación de pueblos, concentrados especialmente en aquellas tierras más cercanas a la estación. 
Es importante señalar que este tipo de núcleos -a los que denominamos, respectivamente, "consolidación de núcleos previos" y "nuevas estaciones"- solía encontrarse a una distancia aproximada de entre 2 y 4 kilómetros del núcleo siguiente, que es la distancia promedio que separaba las estaciones en las zonas más urbanizadas. Incluso en las áreas más consolidadas, en los primeros años de la suburbanización, cada pueblo formaba un núcleo en sí mismo, cuyas dimensiones aparecen determinadas por la distancia que una persona puede caminar de ida y vuelta a la estación. Un emprendimiento característico de este primer periodo de suburbanización, el Barrio Parque Aguirre (San Isidro, 1913), muestra una planta urbana de 20 hectáreas (Figura 3), diseńada de forma tal que incluso los terrenos más alejados no superen las diez cuadras hasta la estación. En este punto nos atenemos a lo que señaló Lewis Mumford (1961) a propósito de los suburbios dependientes del ferrocarril: eran discontinuos y lograron mantener una escala adecuada, no por la intervención de legislación alguna, sino por el límite natural dictado por el traslado a pie.

\section{Localizaciones}

Los mapas que presentamos a continuación ${ }^{6}$ nos permiten analizar el crecimiento y la inserción de los barrios parque para cada uno de los principales ejes de la expansión. En ellos se muestran las "áreas edificadas" (definidas por Cesar Vapñarsky, 2000, como áreas de dos o más edificios por manzana) y los barrios parque en relación con la red de transporte, estaciones ferroviarias y equipamientos deportivorecreativos que se han considerado de importancia.

En el eje norte (Figura 4) se puede ver, para la segunda década del siglo xx, que la población se concentra fundamentalmente en torno a las estaciones ferroviarias. Por su parte, los nuevos núcleos de barrios parque se incorporan al territorio sobre las tierras vacantes a lo largo de los ejes ferroviarios que aglomeran los pueblos de más antigua fundación: el Ferrocarril Mitre, que une las estaciones Retiro-Tigre, y la continuación de la Avenida del Libertador.

Para este mismo periodo, en el eje oeste (Figura 5), los núcleos residenciales alrededor de las estaciones definen un área de ocupación más dispersa y, a su vez, núcleos de menor tamaño, quedando gran cantidad de tierras vacantes sobre la traza del ferrocarril entre un núcleo y otro. En cuanto a los barrios parque, se localizaron, preferentemente, cerca de los núcleos poblados sobre la línea del Ferrocarril Oeste (FCO) y la Ruta $\mathrm{n}^{\circ} 7$ (continuación de la avenida Rivadavia, que se extiende desde la Capital hacia el GBA).

Construcción de la cartografía: en relación con los mapas referidos, para su construcción se ha tomado como base las Cartas Topográficas del Instituto Geográfico Nacional (IGN); allí se han localizado, para cada sección, los emprendimientos que componen nuestro corpus y que corresponden a las incorporaciones de la década del veinte y hasta mediados de los treinta. También se han superpuesto las "áreas edificadas" para 1914, estudiadas por César Vapñarsky (2000) y definidas como áreas con dos o más edificios por manzana. El segundo periodo que comprende nuestra investigación está representado en el segundo mapa de cada sector (Figuras 10, 11, 12). En ellos se localiza la totalidad de urbanizaciones que componen nuestro corpus, si bien se mantiene la diferenciación entre aquellas que corresponden al primer y segundo periodo, junto a las "áreas edificadas" definidas por Vapńarsky para 1948, en donde se incluyen las ya detectadas para el periodo anterior. 
En cambio, en el sector sur (Figura 6), las densidades de población son más altas y prácticamente no se reconocen áreas vacantes sobre la línea que traza el ferrocarril. En contraposición a los dos casos desarrollados, se observa la localización de los primeros barrios parque alejados de la línea principal que aglutina la expansión del eje sur, el Ferrocarril General Roca (FCGR). Dicha situación podría obedecer a la ocupación más densa que ya se verificaba sobre este eje para la segunda década del siglo xx y que no dio lugar a la formación de nuevos asentamientos, sino solo en áreas alejadas de la urbanización.

En efecto, en este primer periodo, las zonas que concentran mayor cantidad de emprendimientos son el eje del Ferrocarril Oeste (50\% de los barrios parque, 19101935) y en segundo lugar, el eje hacia el norte de la Capital (35\% de los barrios parque, 1910-1935). El sector sur, como ya se mencionó, fue el de más temprano crecimiento e, inversamente, el que reconoce la menor incidencia de urbanizaciones de barrios parque (15\% de los barrios parque, 1910-1935) ${ }^{7}$.

FIGURA 4 Eje norte. Localización de emprendimientos de barrios parque y de fin de semana y áreas edificadas, 1935

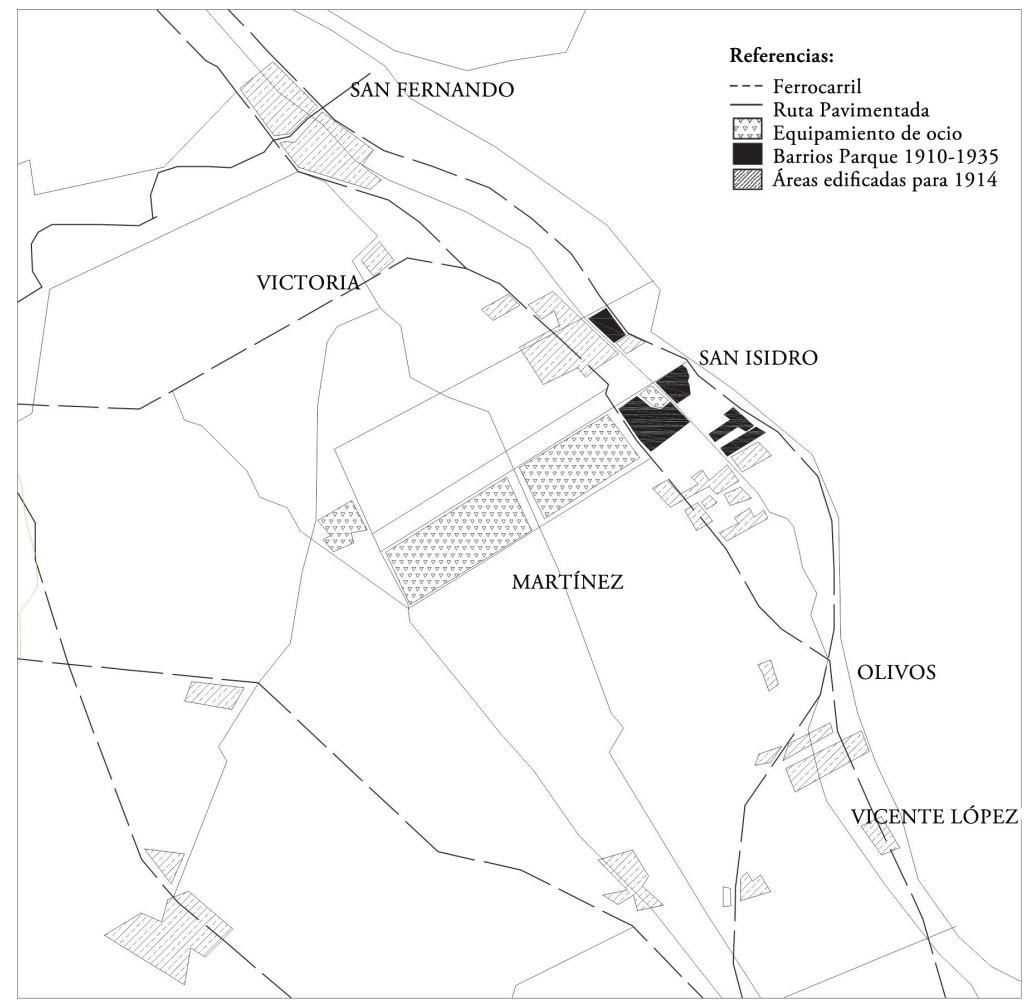

FUENTE ELABORACIÓN PROPIA SOBRE DATOS DE LA CARTA TOPOGRÁFICA DEL INSTITUTO GEOGRÁfiCO NACIONAL. ESCALA: I:I00.000

7 Zona sur (282.137 habitantes), zona norte (140.281 habitantes) y zona oeste (63.863 habitantes). Datos citados por Cesar Vapńarsky (2000), correspondientes al censo de 1914. 
FIGURA 5 | Eje oeste. Localización de emprendimientos de barrios parque y de fin de semana y áreas edificadas, 1935

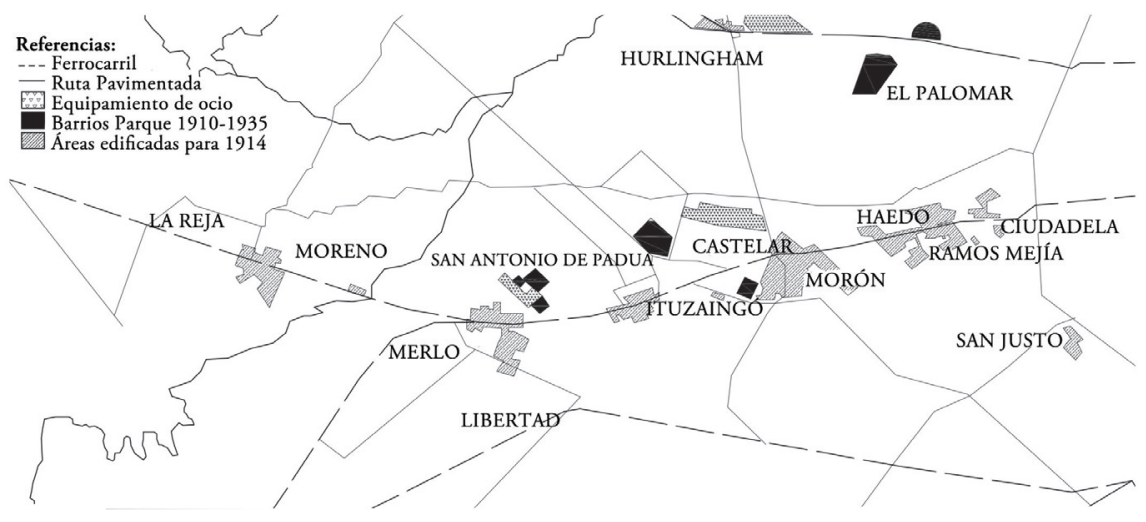

FUENTE ELABORACIÓN PROPIA SOBRE DATOS DE LA CARTA TOPOGRÁFICA DEL INSTITUTO GEOGRÁFICO NACIONAL. ESCALA: I:IOO.OOO

FIGURA 6 | Eje sur. Localización de emprendimientos de barrios parque y de fin de semana y áreas edificadas, 1935

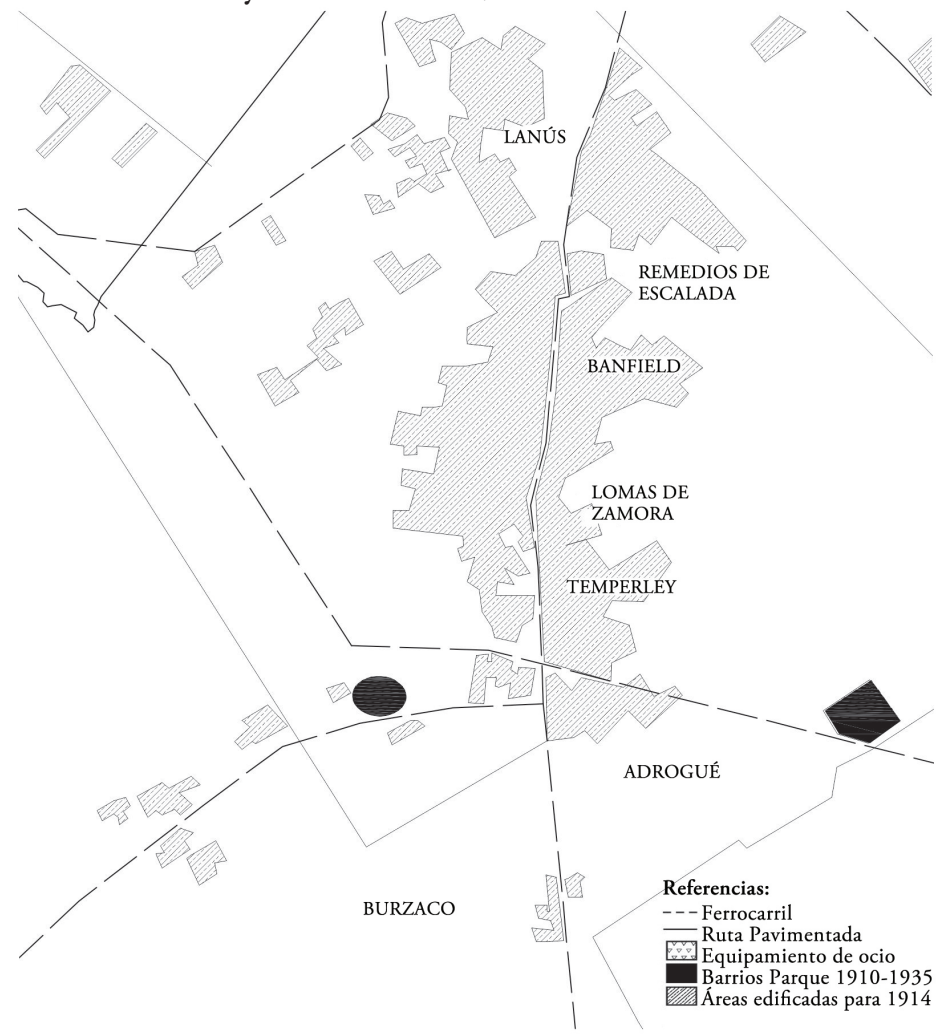

FUENTE ELABORACIÓN PROPIA SOBRE DATOS DE LA CARTA TOPOGRÁFICA DEL INSTITUTO GEOGRÁFICO NACIONAL. ESCALA: I: IOO.OOO 
En otro orden de cosas, una aproximación que analice las variaciones de los valores del suelo en relación con los ejes de la expansión, mostraría, en principio, que el rango en los valores de las cuotas mensuales es muy amplio, con ofertas que van desde 10 pesos argentinos mensuales (Barrio Mattaldi, 1926, General Sarmiento), hasta 160 pesos la mensualidad (Barrio Elortondo, 1931, San Isidro) (véase Cuadro 1). Esta división tan marcada se refleja en el territorio, siguiendo una tendencia según la cual, para igual distancia a la Capital, los partidos de la zona norte concentran los barrios parque que alcanzan los valores del suelo más altos, contra los partidos del oeste, en donde se localizan aquellos barrios que asumen valores del suelo más bajos, al igual que los dos barrios parque alojados para este periodo en la zona sur.

Este panorama obedecería a factores históricos que anteceden a la incorporación de las nuevas urbanizaciones. Entre ellos, la existencia de sectores ya consolidados como áreas recreativas, a lo que se suma la tradición de las antiguas quintas de la elite porteña en zonas tradicionales, como San Isidro (eje norte). Esta configuración determinó una mayor concentración de núcleos nuevos en este sector y los valores superiores que alcanzaron, concordantes con la formación de un área residencial más homogénea y consolidada, en comparación con el crecimiento mucho más lento registrado en el sector oeste. En este sentido, la localización espacial era un componente importante que determinaba las posibilidades de éxito y el carácter que tomarían los emprendimientos, según fueran las facilidades de acceso con que contaban, y su cercanía a zonas productivas o clubes deportivos y a otros núcleos de veraneo ya legitimados. La localización espacial también determinaba diferencias entre los sectores sociales que podían acceder o no al emprendimiento, considerando las variaciones del costo de la tierra y procesos de suburbanización de más larga data, que marcaban un contraste socioespacial entre las direcciones que tomaba la expansión.

Finalmente, lo que podemos ver en el proceso expansivo del GBA es que, recién hacia la década de los treinta, comenzaron a distinguirse indicios de una nueva transformación. En los sectores más consolidados de la expansión, se verifica una mayor actividad inmobiliaria, en general, y una mayor cantidad de loteos periféricos de pequeñas dimensiones que se anexan a los trazados originales de los pueblos, generando las primeras señales en la trasformación del carácter suburbano. En la misma dirección, la mayor cantidad de loteos en la periferia de un área estaría dando cuenta de un nivel de consolidación creciente en las zonas "centrales" del núcleo de referencia, que haría posible la incorporación de nuevos terrenos al mercado. De hecho, los primeros loteos de este tipo se registraron en zonas intermedias a núcleos del eje norte -"15 lotes de la antigua quinta Lezica" o "18 lotes lindando con el B.

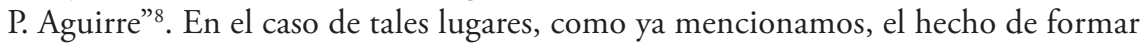
parte de un cordón de suburbanización que presentaba señales de transformación, y la existencia de una población cercana de mayor importancia y tamaño, generaron un efecto de renovación en las zonas intermedias y de atracción hacia nuevas inversiones y emprendimientos. 
Hacia la década de los treinta, los efectos de la expansión urbana se empezaron a sentir sobre las zonas rurales, que comenzaron a desaparecer a causa de loteos y urbanizaciones. Sin embargo, salvo en sectores muy particulares de la expansión, durante este período se conservó el esquema materializado a fines del siglo XIX, de la ciudad capital con su constelación de suburbios vinculados por los ferrocarriles.

\section{El ciclo 1935-1950}

\section{FIGURA 7 | Expansión del GBA para 1948}

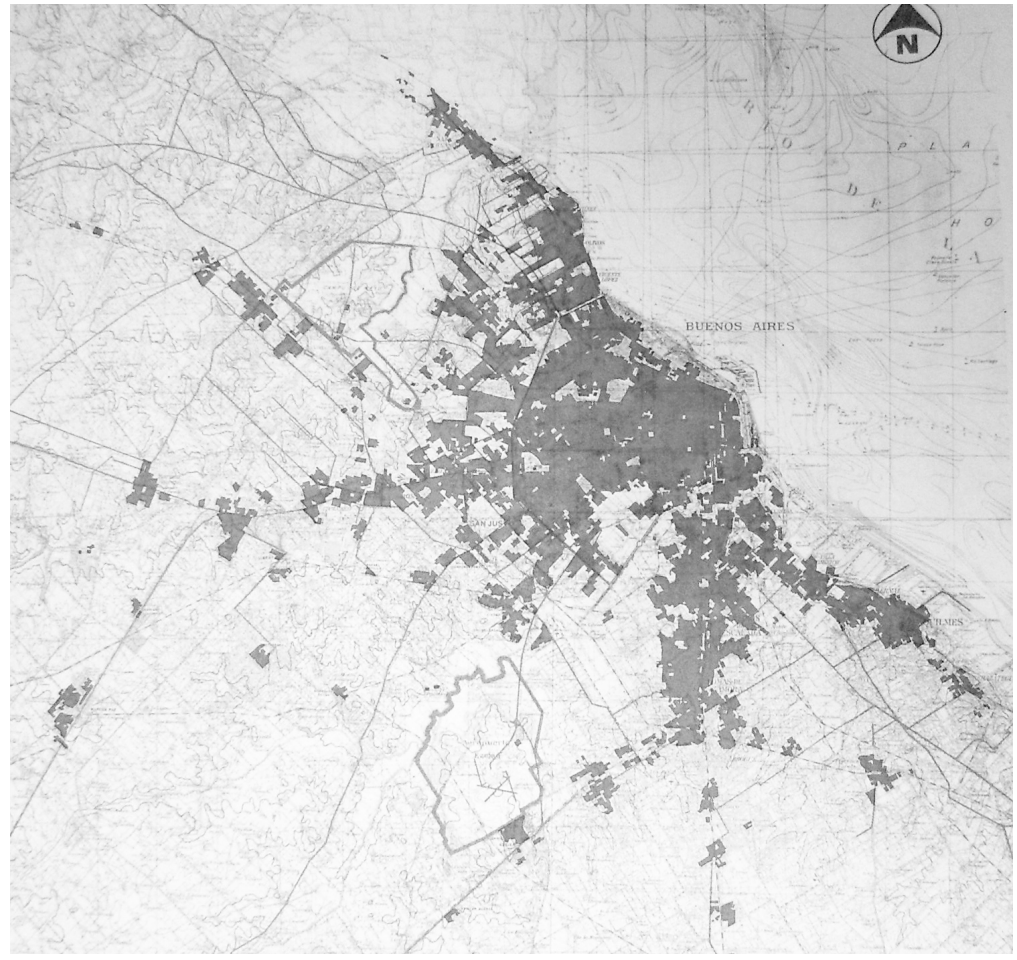

FUENTE RANDLE (1987)

\section{Un panorama...}

En el segundo período de suburbanización, aumentó enormemente la cantidad de emprendimientos que se incorporaron al mercado inmobiliario. En estos quince años, 1935 a 1950, se concentra el $80 \%$ del total de los núcleos de barrios parque y de fin de semana que analizamos en el Gran Buenos Aires. Especialmente, los loteos aumentaron hacia fines del periodo, cuando se hizo factible obtener tasas de beneficio más altas que en otros sectores de la economía, como consecuencia de la mayor demanda de lotes urbanos y del proceso inflacionario que se desencadenó hacia mediados de los ańos cuarenta y generó un flujo de capitales hacia el mercado de tierras (Clichevsky, 1975). 
Siguiendo la tendencia que ya se perfilaba en el periodo anterior, la distribución geográfica de los emprendimientos distó de ser homogénea. El mapa que muestra la localización de los emprendimientos (Figura 7) deja ver que ellos se concentraron en algunos partidos del norte y noroeste, especialmente San Isidro, Morón, Moreno y Merlo, que sumaron más del 50\% de los emprendimientos correspondientes al total del área (17 partidos). $\mathrm{Al}$ interior de estos partidos se generaron patrones de asentamiento disperso, como producto de la configuración más homogénea de vías de acceso que permitía el automotor en contraste con el trazado ferroviario. A pesar de que las principales carreteras siguieron recorridos similares a los que ya tenía el ferrocarril, algunas vías de importancia secundaria aparecían de manera transversal a las vías de tránsito principales, dando lugar a nuevas áreas de crecimiento.

Como la campaña de Ford subrayaba astutamente en una publicidad, el automóvil particular posibilitaba un movimiento más libre que, junto a la ampliación de la red de carreteras, daba lugar a la conformación de una trama más homogénea que la que se desprendía del ferrocarril ${ }^{9}$. En particular, algunas de estas nuevas vías, como la avenida Gaona (que atraviesa parte de la zona oeste, desde Ciudadela hasta Moreno, con recorrido perpendicular a la avenida General Paz), o el Camino de Cintura (vía que corre paralela a la avenida General Paz, atravesando varios partidos del GBA, a una distancia de entre 10 y 15 kilómetros por fuera de la primera), tendieron a concentrar en sus márgenes gran cantidad de operaciones.

En relación directa con la ampliación de los suburbios y con las nuevas vías que penetraban en el territorio, se comprueba que en este periodo predominaron dos tipos de loteos: aquellos de dimensiones menores, que se anexaron a aglomeraciones de cierta importancia, a los que denominaremos "loteos periféricos"; y loteos de grandes dimensiones, a los que denominaremos "loteos sueltos", ubicados sobre las nuevas rutas intersticiales. Como veremos, algunos de estos últimos cumplieron una función fundamental, al guiar nuevos sectores de la expansión, mientras que otros, en menor proporción, permanecieron como puestos de avanzada de una expansión que nunca terminó de consolidarse.

Los primeros emprendimientos mencionados -loteos periféricos- surgieron en gran medida como resultado de un proceso de densificación en áreas preexistentes, donde la aparición de algunos loteos pequeños ilumina un proceso de subdivisión que alcanzó la escala de los particulares, que loteaban sus propias viviendas ante el negocio ventajoso que prometía la expansión. Los segundos -loteos sueltos- se reconocerían si pusiéramos la lupa en alguna de las vías mencionadas. Estas concentraron la mayor cantidad de tales emprendimientos, los cuales tendieron a agruparse de manera consecutiva, o enfrentados. En general, lo hicieron aprovechando ya sea una calle principal -muchas veces la única pavimentada de la zona o aquella que cobraba importancia al unir polaridades destacadas dentro del tejido urbano-, el éxito que pudiera generar un loteo vecino anterior, en el que ya se observaban un Ford y adquiera cabal conocimiento de todos los barrios de la ciudad y de sus pintorescos alrededores. Guíe usted mismo. Vaya por la calle o camino que le parezca más interesante". (Publicidad de Ford, en Femenil 14/09/1925, s/p.) 
algunas construcciones o, mejor aún, la existencia de un club que se convertía en la principal referencia para los emprendimientos vecinos.

\section{Localizaciones}

En relación con los ejes de la expansión, la incidencia de los loteos periféricos fue más notoria en la zona norte, y la de los loteos sueltos, en la zona oeste. En el sector sur, aunque se reconoce la existencia de ambos tipos -como puede constatarse en la Figura 12-, su incidencia en relación con el total de "áreas edificadas" es exigua.

Como muestra la Figura 10, de los barrios parque incorporados durante el segundo período en la zona norte, una parte contribuyó a densificar las áreas residenciales sobre el eje de crecimiento tradicional, aquel que se había consolidado durante el primer periodo. Respecto de la mitad restante, puede decirse que se incorporó en busca de nuevas áreas de crecimiento que, para 1948, solo parcialmente quedaron anexadas a la expansión.

Figura 8 | Núcleo de barrios parque en torno al Camino de Cintura, 1947

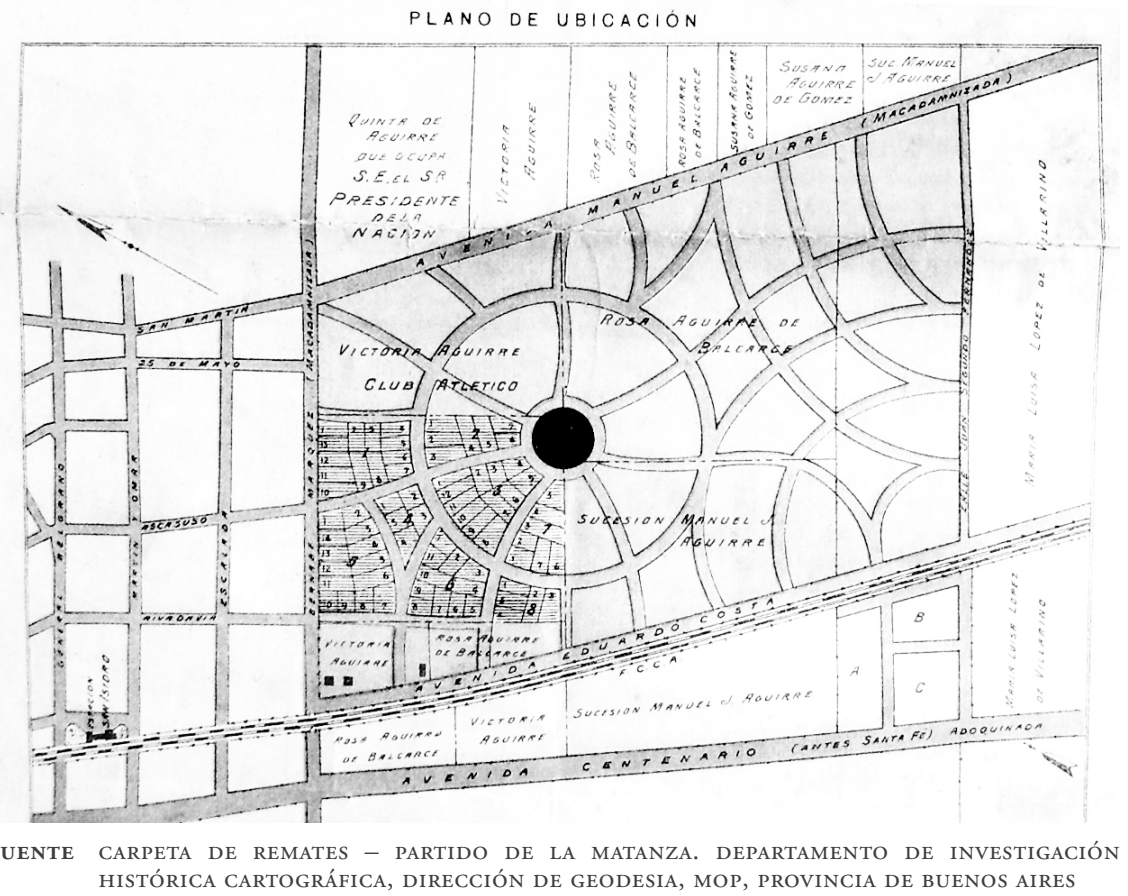

En cuanto al sector oeste, particularmente en las áreas urbanas que incorporaron mayor número de urbanizaciones de barrios parque, como pueden ser Castelar e Ituzaingo, el mapa construido (Figura 11) muestra una cantidad considerable de loteos pequeńos y medianos, que en un primer momento contribuyeron a consolidar núcleos preexistentes y que más tarde se anexaron, generando nuevas áreas de expansión. Ambos tipos favorecieron la consolidación de áreas urbanas en las que 
predominó un crecimiento de baja densidad, caracterizado por tipologías residenciales compactas de perímetro libre e imágenes pintoresquistas que mayoritariamente se asociaban a estos núcleos (Gómez Pintus, 2011). Siguiendo otras lógicas, pero en esta misma línea, los loteos de mayores dimensiones -casi exclusivamente aquellos que denominamos como "sueltos"- se introducían en áreas alejadas, predominantemente rurales, en las cuales -si los emprendimientos llegaban a ser exitosos- se generaba un pequeño "campo de acción" que atraía nuevos loteos.

Un caso significativo de este tipo de agrupamiento se registró sobre el Camino de Cintura (Figura 8), cerca de la estación Morón, donde se agrupó una serie de emprendimientos, iniciados con el loteo del Barrio Parque Peluffo (1945), al que le siguieron el Barrio Parque San Eduardo (sin fecha), el Barrio Parque General San Martín (1945), el Barrio Parque La Ganga (1947), una nueva fracción del Barrio Parque Peluffo (1949) y los barrios parque Golden Park (1949) y Los Pinos (1950).

De una situación similar da cuenta el núcleo que se formó en Don Torcuato (Figura 9). Luego de que hacia fines de la década del treinta se construyera el Hindú Club, se lotearon el Barrio Parque Sancalal (1948) frente al Hindú Club y, lindando con este, el Barrio Parque Guadalupe (1948) y la nueva fracción del Barrio Parque Guadalupe (1950; sin fecha, pero se promociona mencionando el loteo anterior).

Figura 9 | Núcleo de barrios parque en torno a la estación Don Torcuato y al Hindú Club, circa 1948

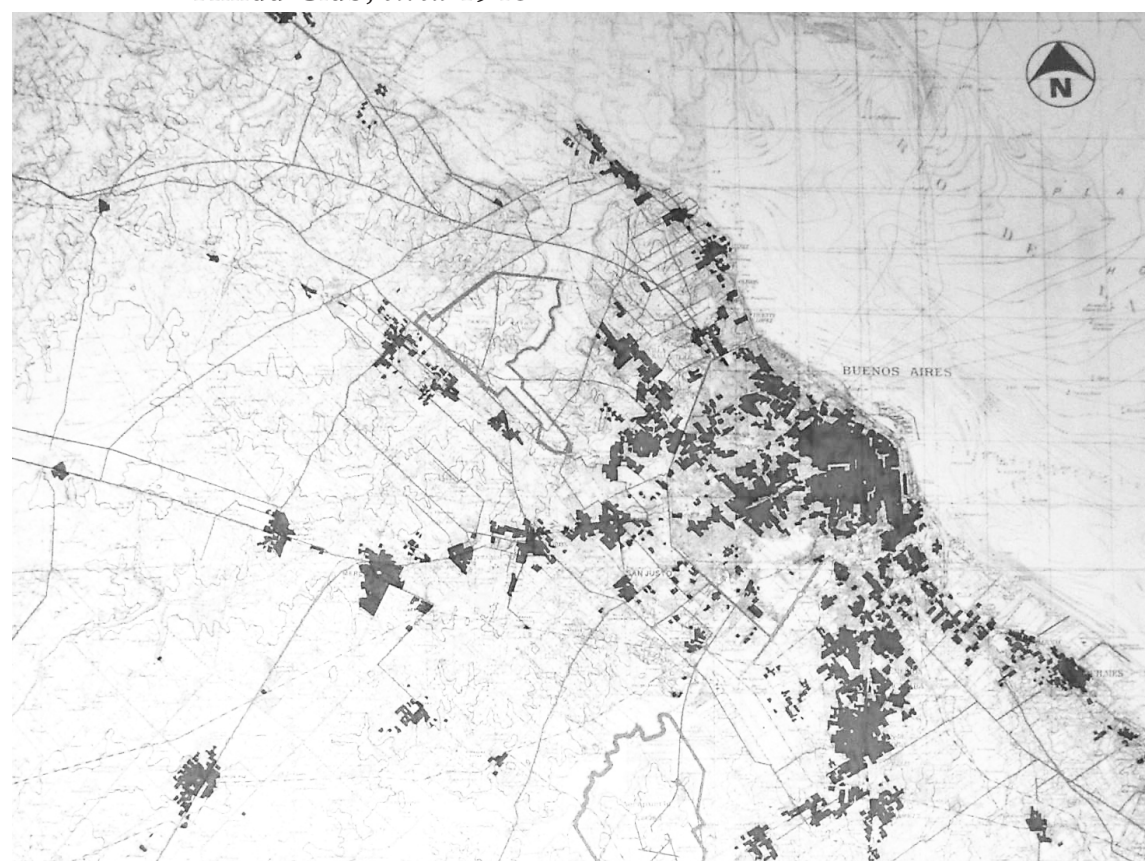

FUENTE CARPETA DE REMATES - PARTIDO DE TIGRE. DEPARTAMENTO DE INVESTIGACIÓN HISTÓRICA CARTOGRÁFICA, DIRECCIÓN DE GEODESIA, MOP, PROVINCIA DE BUENOS AIRES 
Mediante este tipo de agrupamiento se generaba paulatinamente la urbanización de un área. No todos los loteos que en ella se realizaban eran reconocidos necesariamente como barrios parque. Algunos eran simples parcelamientos que seguían la tendencia predominante en el área, la cual empezaba a adquirir así un carácter diferencial, suburbano, que la distinguía en medio del paisaje predominantemente rural y la perfilaba como un enclave modernizador de referencia.

En menor medida, también se asistió al caso contrario: varios de los "loteos sueltos" de grandes dimensiones solo llegaron a ser ocupados en un 10 o $20 \%$ de su capacidad, sus tierras permanecieron vacantes durante décadas, como recordatorio de las ambiciones desmedidas y de los intentos fallidos a los que la expansión también dio lugar. Pueden mencionarse como ejemplo los casos del Barrio Parque San Martín (sin fecha), en Merlo; Estación Agustín Ferrari (1950), también en Merlo; o el Barrio Parque Ibáñez (1947), en La Matanza.

FIgURA Io | Eje norte. Localización de emprendimientos de barrios parque y de fin de semana y "áreas edificadas”, 1948
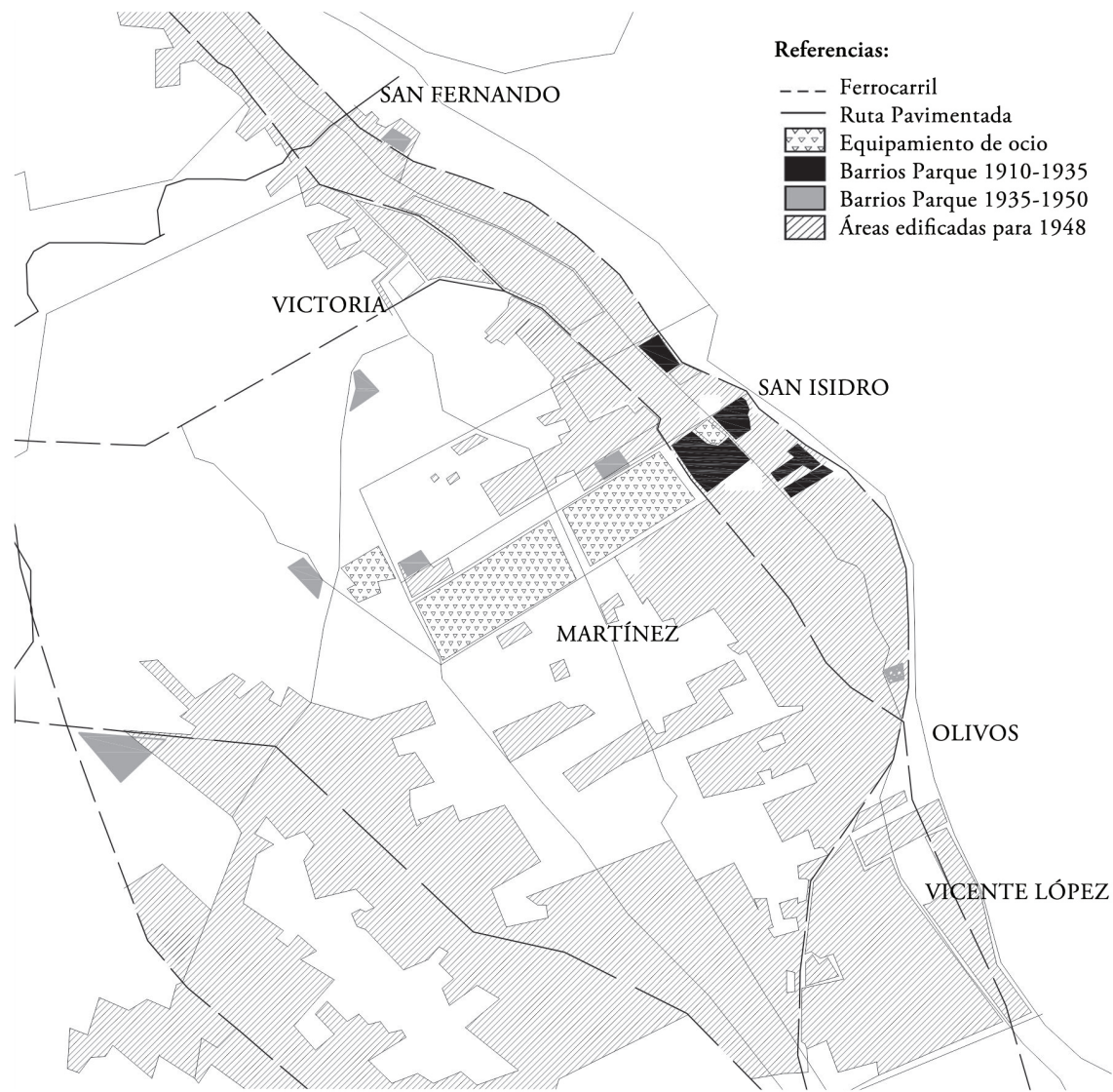

FUENTE ELABORACIÓN PROPIA SOBRE LA CARTA TOPOGRÁFICA DEL INSTITUTO GEOGRÁFICO NACIONAL. ESCALA: I: I OO.OOO 
FIGURA I I | Eje oeste. Localización de emprendimientos de barrios parque y de fin de semana y "áreas edificadas”, 1948

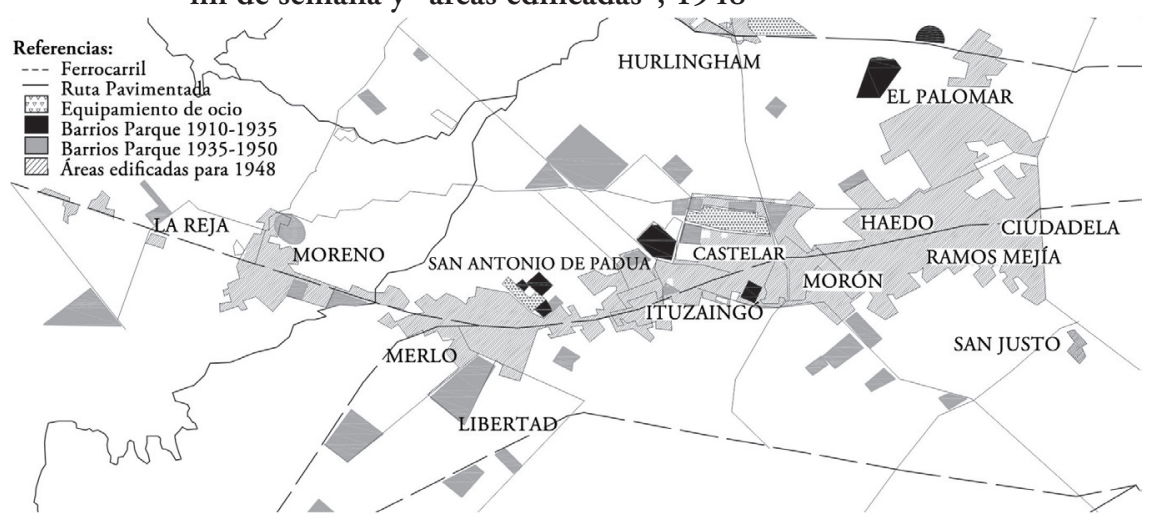

FUENTE ELABORACIÓN PROPIA SOBRE LA CARTA TOPOGRÁFICA DEL INSTITUTO GEOGRÁFICO NACIONAL. ESCALA: I:IOO.OOO

FIGURA I2 | Eje sur. Localización de emprendimientos de barrios parque y de fin de semana y "áreas edificadas", 1948

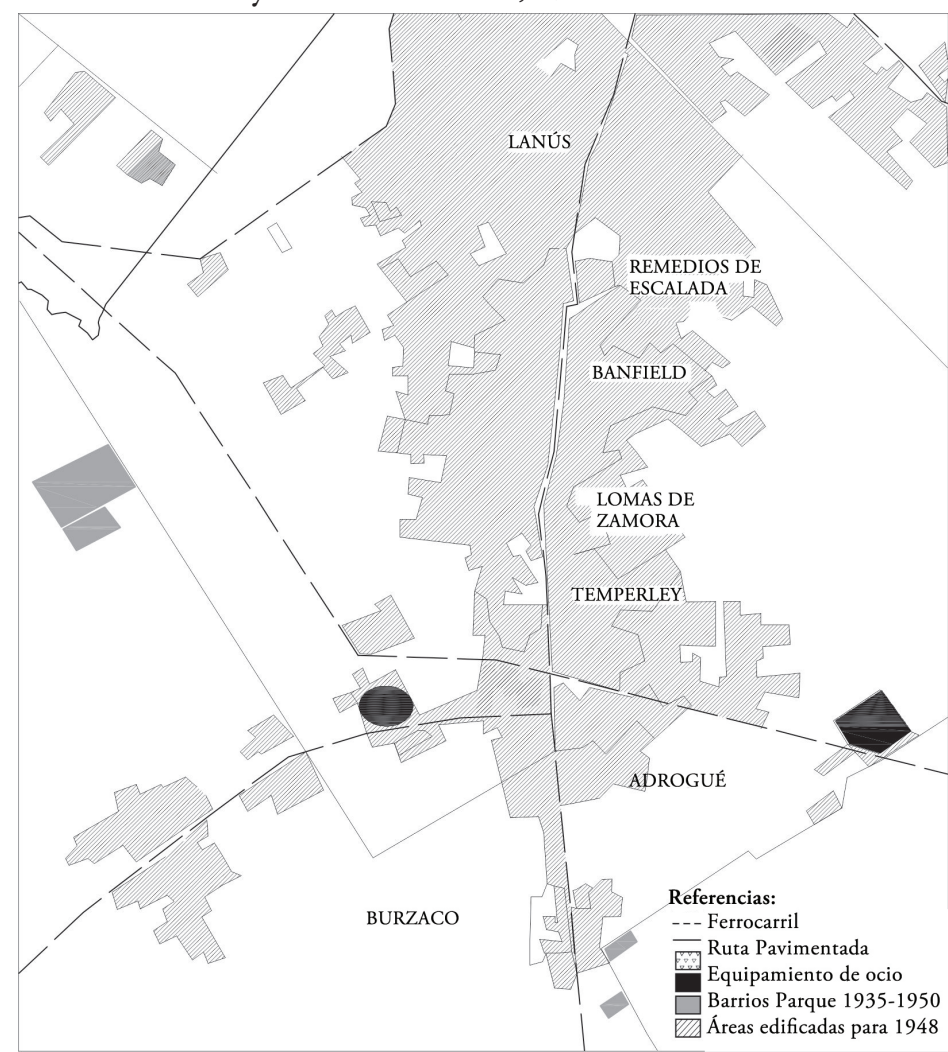

FUENTE ELABORACIÓN PROPIA SOBRE LA CARTA TOPOGRÁFICA DEL INSTITUTO GEOGRÁFICO NACIONAL. ESCALA: I: IOO.0OO 
Desde otra perspectiva, los loteos que se ofrecían formando parte, o como ampliación de lo que los contemporáneos llamaban un núcleo "progresista" ${ }^{10}$, tenían mayores posibilidades de venta y de alcanzar valores más altos respecto del promedio de ese partido.

En cuanto a este último punto -los valores del suelo que asumieron los ejes de la urbanización-, se repiten las marcadas diferencias que ya observamos para el periodo anterior. Tres partidos (Morón, Moreno, Merlo), dentro del eje de crecimiento hacia el oeste, asumieron valores del suelo promedio en un rango bajo y medio -respectivamente, entre 5 y 25 pesos mensuales, y entre 25 y 100 pesos mensuales-; y un único partido (San Isidro, dentro del eje de crecimiento hacia el norte) mostró valores promedio más altos -mayores a los 100 pesos la mensualidad.

Los valores del suelo generales para el sector norte se ubicaron alrededor de un $75 \%$ por encima de aquellos de localidades situadas a igual distancia de la Capital en la suburbanización oeste, y más de un $100 \%$ por encima de los loteos en el sudoeste. Como ya seńalamos, en su mayor parte las urbanizaciones de la zona norte se localizaron en intersticios vacantes de zonas predominantemente urbanizadas, lo cual daría como resultado que el total de estos loteos presentara valores superiores a los otros ejes, con cuotas que excedían los 100 pesos mensuales. Algunos ejemplos concretos nos lo proporcionan el Barrio Parque Vivot, con cuotas de 125 pesos para el año 1935, o el Barrio Parque Balcarce, con lotes algo más grandes y cuotas de 170 pesos para el mismo ańo. Como puede observarse en el Cuadro 1, en ninguno de estos loteos se ofrecieron plazos de venta tan extendidos como aquellos que se ofrecían en los loteos populares. Este tema ya fue señalado por Charles Sargent (1974), quien reconoció la reducción en el número de cuotas y en los plazos de pago como una de las estrategias más aplicadas a la hora de generar áreas residenciales segregadas, en las que se pretendía excluir a los sectores de menores recursos. Tengamos en cuenta, por ejemplo, que para este periodo los datos obtenidos del Departamento Nacional de Trabajo muestran una estimación del costo de vida de una familia en 160 pesos mensuales, el sueldo promedio de un obrero alcanzaba los 150 pesos mensuales y el de un oficial, por ejemplo ferroviario, los 450 pesos mensuales ${ }^{11}$. Son cifras que nos sirven para estimar los grupos sociales que podían acceder a cada sector.

\section{A modo de cierre}

Concluyendo, observamos que, durante los primeros años, los nuevos loteos perpetuaban un esquema de crecimiento radial basado en los tres principales ejes

10 Así se calificaba en las publicidades a algunas de las áreas de mayor crecimiento; por ejemplo: "rodeados de espléndidos chalets y casas quinta en un paraje alto y sano de los alrededores de la Capital, ideal para vivir o para quinta de recreo. Próximo al progresista pueblo de Hurlingham”, propaganda de un loteo en el ańo 1929 (Carpeta de Remates Partido de General Sarmiento, Departamento de Investigación Histórica Cartográfica, Dirección de Geodesia, Mop, Provincia de Buenos Aires). O "una zona progresista entre Castelar e Ituzaingo", propaganda de un loteo en el año 1946 (Carpeta de Remates Partido de Morón, Departamento de Investigación Histórica Cartográfica, Dirección de Geodesia, Mop, Provincia de Buenos Aires).

11 Estos datos pertenecen al Boletín Mensual del Departamento Nacional de Trabajo, noviembre 1932; y Boletín Informativo del Departamento Nacional de Trabajo, enero, febrero, marzo 1936. 
ferroviarios delineados en el siglo XIX y cuya primacía comenzaría quebrarse a lo largo del periodo. Estos ejes nacían con una densidad habitacional más marcada en los bordes de la Capital, la cual iba disminuyendo a medida que se alejaban de ella. En el otro sentido, de crecimiento concéntrico, los nuevos loteos establecían una porción territorial en forma de anillo, alejada entre 20 y 40 kilómetros de la Capital, que quedaba más definida entre los ejes norte y oeste y se desvanecía hacia el sur. Esta figura se fue consolidando a lo largo de dos momentos, entre 1910 y 1935, y entre 1935 y 1950.

En una primera instancia, se mantuvo el esquema cristalizado en el siglo XIX, el de la ciudad matriz con su constelación de suburbios vinculados por el ferrocarril. A lo largo de estos primeros años se asistió a un proceso de suburbanización incipiente, en donde los nuevos loteos se introdujeron sobre los ejes norte y oeste, especialmente, en torno a nuevas paradas del ferrocarril o en las pequeńas porciones que permanecieron vacantes en el entorno inmediato de los pueblos fundados en el siglo xIx. Más precisamente, el análisis de las localizaciones mostró que, hacia el norte, los núcleos residenciales se concentraron fundamentalmente en las áreas vacantes a lo largo de los ejes ferroviarios; y en el oeste, especialmente, cerca de los núcleos poblados que ya existían sobre esta misma línea. Estas intervenciones consagran, en orientación norte, las tendencias de urbanización residencial y recreativa. En orientación oeste, por su parte, la convivencia de distintas actividades, junto a la permanencia de grandes áreas vacantes, impidió la definición de una identidad. En contraste, en el sur se perciben diferencias notables, pues las pocas propuestas de barrios parque se ubican lejos de la traza ferroviaria, cuyos bordes ya presentaban un importante nivel de consolidación desde inicios del siglo.

En su configuración, los núcleos que dieron lugar a la expansión en las décadas de los años diez y veinte se organizaron en forma compacta y autocontenida. Los que se localizaron sobre la nuevas estaciones, en tanto generaron núcleos ex novo, ocuparon áreas de mayores dimensiones, pero estuvieron naturalmente limitados por la imposibilidad de recorrer largas distancias a pie.

Estas características se irían modificando a lo largo del ciclo 1935-1950, cuando se experimentó el boom de los loteos suburbanos en el marco de muy diversas tendencias de localización. En el nuevo escenario, se pueden identificar las huellas de una urbanización dispersa en relación con la accesibilidad, modalidad hecha posible por las vías de acceso y el automóvil, en contraposición a la organización en torno a ejes jerárquicos bien marcados del periodo anterior.

En efecto, la década del cuarenta fue testigo de una expansión del mercado de tierras sin precedentes, cuando en este sector de la economía fue posible obtener tasas de ganancias más altas que en otros ámbitos. Al mismo tiempo, las estrategias estatales desplegadas para la construcción de caminos a partir de la década del treinta, ya dejaban ver nuevas rutas y calzadas adentrándose en el área metropolitana. Este fenómeno generó condiciones que hicieron posible la ocupación de áreas intersticiales y, en el largo plazo, el pasaje hacia una urbanización dispersa, aunque simultáneamente se consolidaban algunas de las diferencias que marcamos para el periodo previo. Sobre el eje sur, la incidencia de este tipo de urbanizaciones siguió siendo exigua frente al tipo de loteo urbano tradicional del área. 
Contemporáneamente, los pequeños loteos del norte contribuían a densificar las áreas de ocupación tradicionales, entre la Avenida del Libertador y el eje del ramal ferroviario Retiro-Tigre, mientras que una amplia gama de urbanizaciones de mayor tamaño fue gestando nuevas áreas de crecimiento. En el oeste, se experimentó el mayor incremento de barrios parque que, al igual que en el norte, contribuyeron a consolidar núcleos previos y áreas suburbanas en las que predominó el crecimiento de baja densidad. Más importante, sin embargo, fue el papel que desempeñaron los loteos de grandes dimensiones, ubicados sobre nuevas vías de acceso en áreas predominantemente rurales, que funcionaron como punta de lanza para futuros procesos de suburbanización y dieron lugar a una notable variedad de situaciones registradas sobre este eje.

Algunos rasgos de este nuevo orden arrojaron como resultado la desaparición de los pequeños núcleos organizados en torno a las estaciones de ferrocarril. Ellos atravesaron un proceso de transformación generado por la adición de loteos periféricos de menor extensión, que en buena medida contribuyeron a desdibujar los límites del núcleo original y, en consecuencia, aportaron a homogeneizar algunos sectores de la expansión.

Los loteos de grandes fracciones ubicados sobre las rutas y caminos recientemente abiertos fueron, sin embargo, la figura destacada de este periodo. A lo largo de la década del cuarenta, a medida que estos núcleos suburbanos se alejaban del ferrocarril y de los espacios de significación de la comunidad, el suburbio dejó de ser una unidad vecinal para convertirse en una extensión difusa, que por sus características físicas debió renunciar a conformar una comunidad suburbana o entidad similar al barrio como artefacto de identidad cultural y política. Situados dentro de la línea del barrio jardín, marcaron un punto de inflexión en la tradición del suburbio como comunidad y espacio de sociabilidad, vinculándose así a futuros procesos de suburbanización de las elites de los años noventa.

A través del reconocimiento de sus huellas, este artículo ha buscado ser también una invitación a reflexionar sobre la condición de perdurabilidad del territorio, entendido, según sugiere Leonardo Benévolo (1993), como "canal de comunicación entre presente y pasado". 


\begin{tabular}{|c|c|c|c|c|c|c|c|c|c|c|c|c|c|c|c|c|c|c|c|c|}
\hline 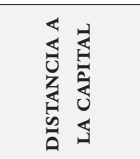 & 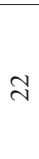 & $\approx$ & $\stackrel{\sim}{\sim}$ & $\stackrel{\infty}{\sim}$ & ㄱ & $\vec{\sim}$ & $\cong$ & mे & 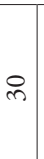 & m & ঙ্ & 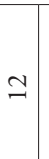 & $\stackrel{\infty}{-}$ & $\approx$ & $\ddot{\sim}$ & $\ddot{\sim}$ & $\stackrel{\sim}{\sim}$ & $\stackrel{\infty}{\sim}$ & $\underset{\sim}{\sim}$ & $\widetilde{N}$ \\
\hline 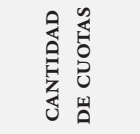 & $\stackrel{8}{\circ}$ & $\stackrel{\text { త్ }}{ }$ & & 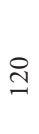 & 0 & $\stackrel{\text { త్ }}{ }$ & § & & & & & & 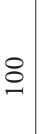 & 0 & & 0 & ㄱ. & $\underset{\text { త }}{ }$ & & \\
\hline $\begin{array}{l}\mathbb{4} \\
0 \\
0 \\
0 \\
\vdots\end{array}$ & نَ & نُ & $\hat{E}$ & نُ & نُ & $\hat{A}$ & 디 & $\dot{\leftrightarrow}$ & نَّ & $\dot{\oplus}$ & $\hat{\mathrm{A}}$ & $\hat{\mathrm{E}}$ & & نَ & نَّ & ن் & ن & $\dot{\oplus}$ & & \\
\hline 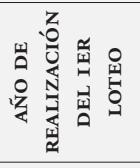 & $\underset{\approx}{\curvearrowright}$ & $\frac{\nabla}{\omega}$ & 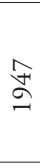 & 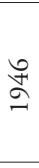 & $\begin{array}{l}\stackrel{\sim}{\approx} \\
\stackrel{\Omega}{ }\end{array}$ & \begin{tabular}{l} 
o \\
\multirow{2}{2}{}
\end{tabular} & 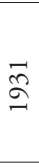 & $\begin{array}{l}\text { †े } \\
\stackrel{2}{二}\end{array}$ & $\stackrel{f}{\curvearrowright}$ & 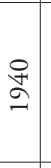 & $\underset{Ð}{\stackrel{+}{\Xi}}$ & $\begin{array}{l}\stackrel{2}{\cong} \\
\stackrel{\Omega}{ }\end{array}$ & 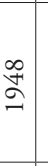 & $\stackrel{\mathscr{\vartheta}}{\stackrel{+}{二}}$ & $\stackrel{\sim}{\stackrel{2}{\sigma}}$ & $\begin{array}{l}\stackrel{\curvearrowleft}{\leftarrow} \\
\curvearrowright\end{array}$ & $\stackrel{\overbrace{}}{\stackrel{F}{二}}$ & $\begin{array}{l}\curvearrowleft \\
\stackrel{\sigma}{\beth}\end{array}$ & $\begin{array}{l}\stackrel{2}{\Omega} \\
\approx\end{array}$ & $\stackrel{\sim}{\stackrel{\sim}{\sigma}}$ \\
\hline
\end{tabular}

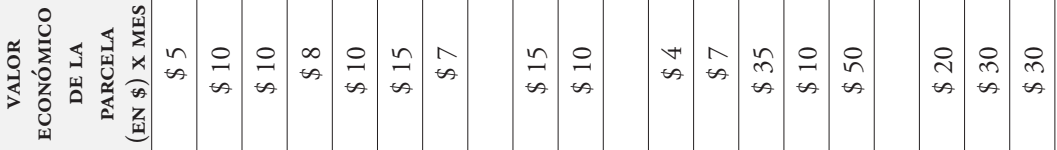

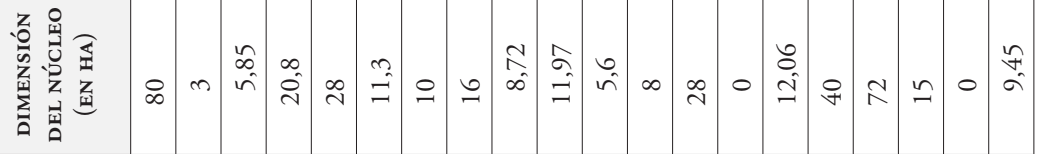

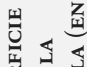

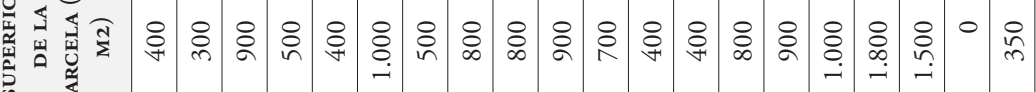

อี क s

空

¿

0
0
0
0
0
0
0
0
0
0
0
0
0
0
0

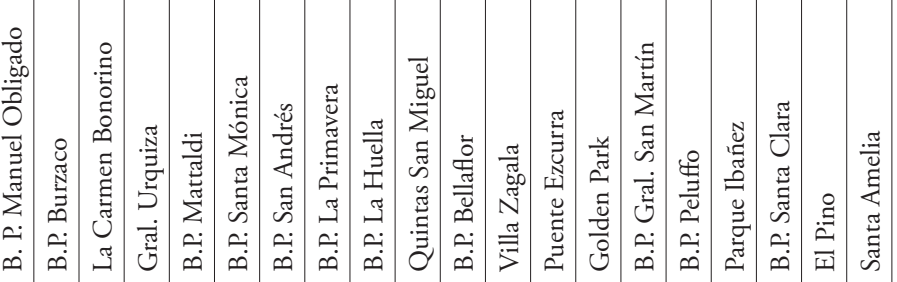

突

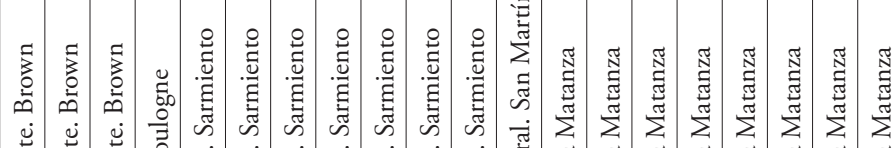

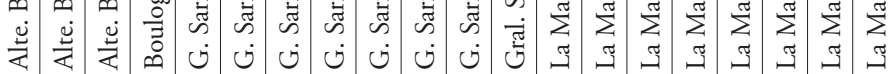

:

\begin{tabular}{|c|c|c|c|c|c|c|c|c|c|c|c|c|c|c|c|c|c|c|c|}
\hline- & $\sim$ & $n$ & tr & $n$ & $\bullet$ & $\Lambda$ & $\infty$ & $a$ & 으 & $=$ & 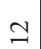 & 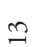 & \pm & 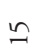 & 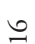 & 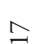 & $\infty$ & $\approx$ & \\
\hline
\end{tabular}




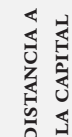

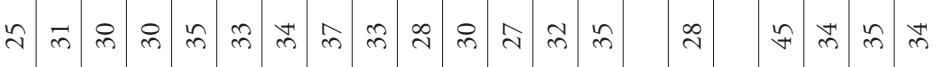

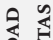

象

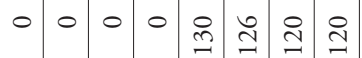

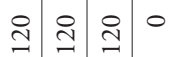

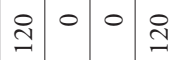

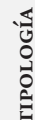

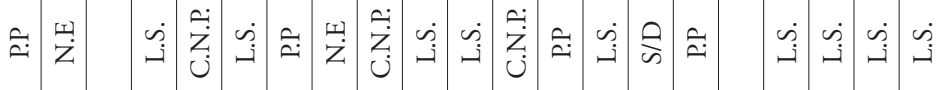

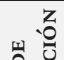

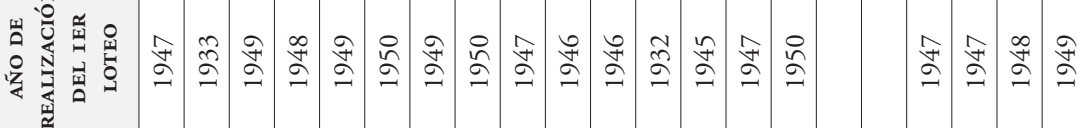

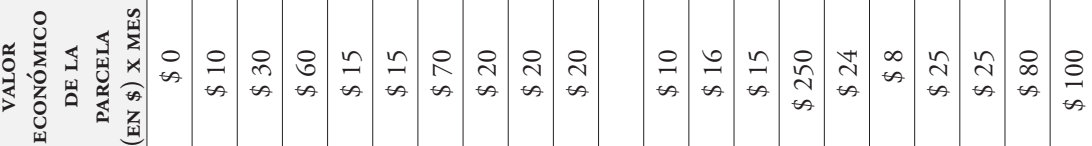

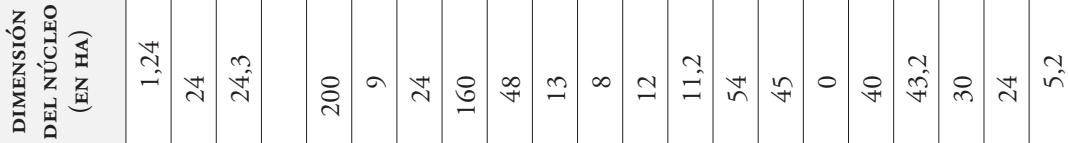

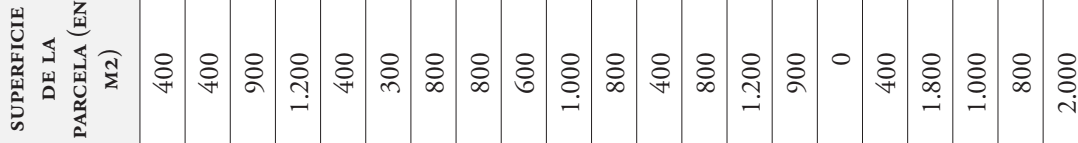

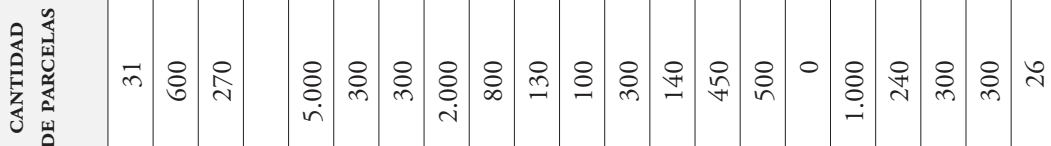

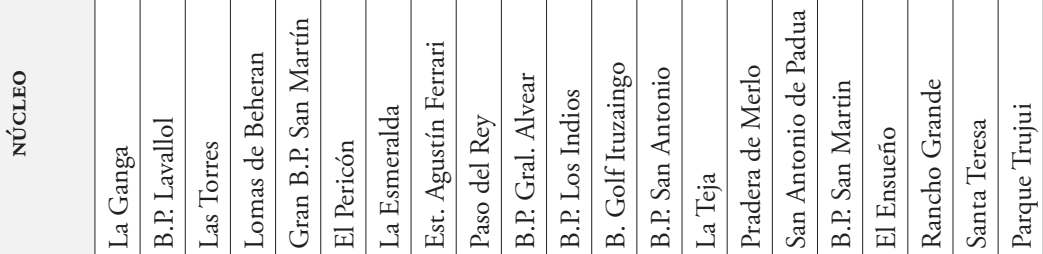

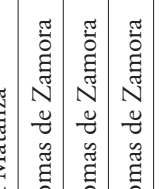

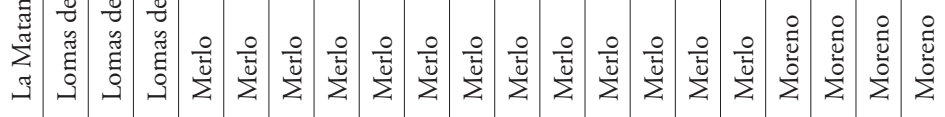

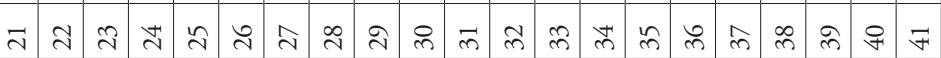




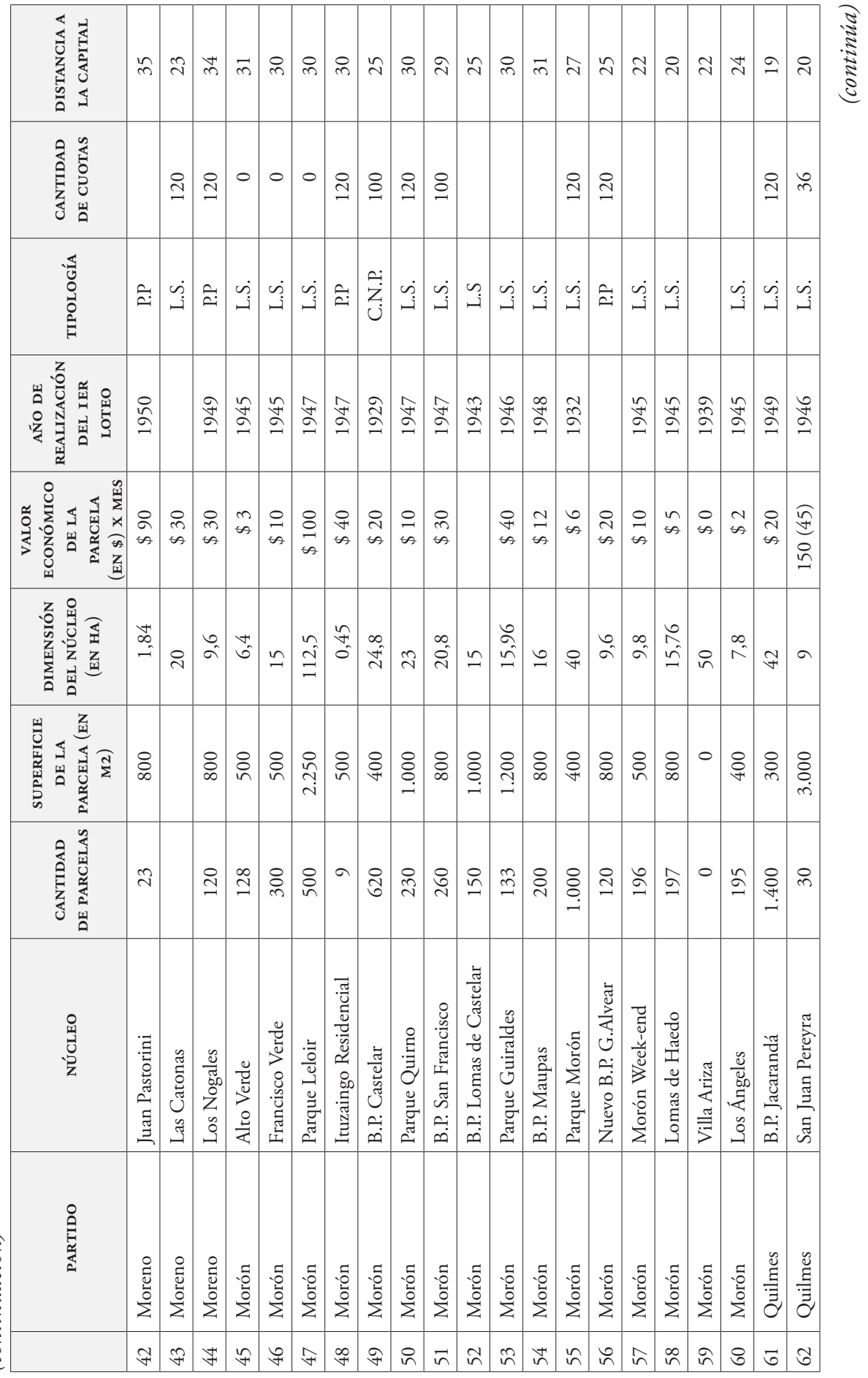




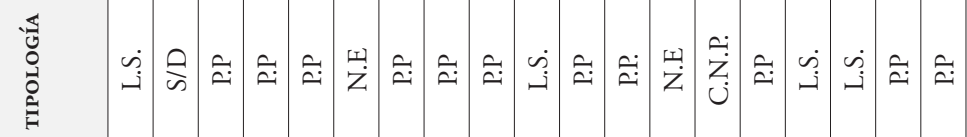

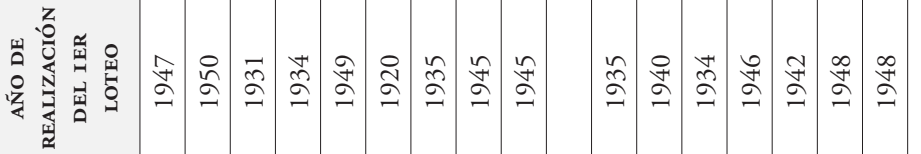

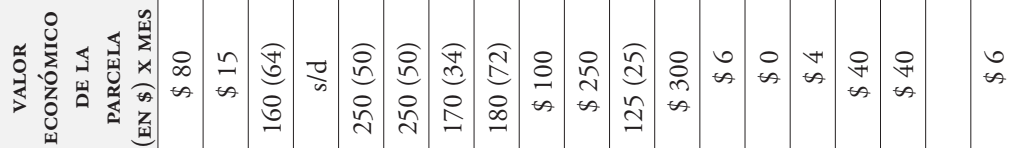

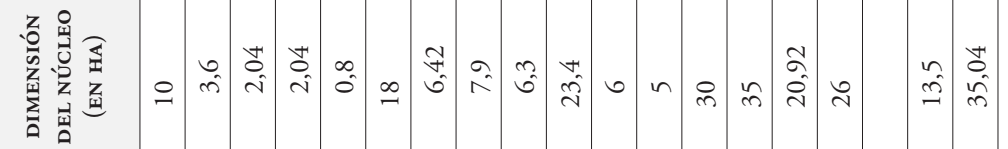

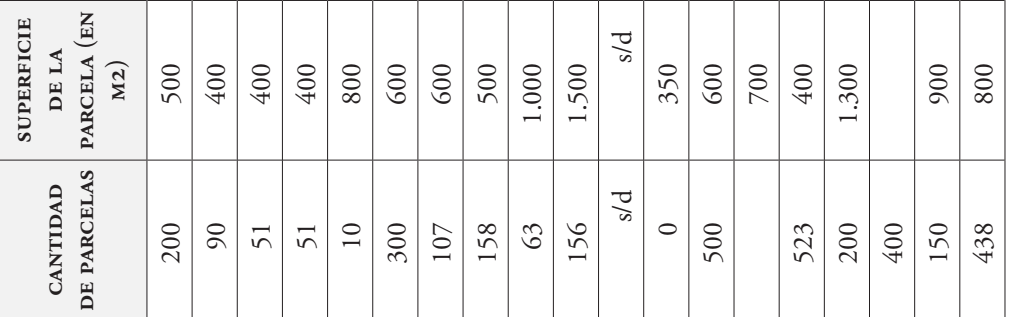

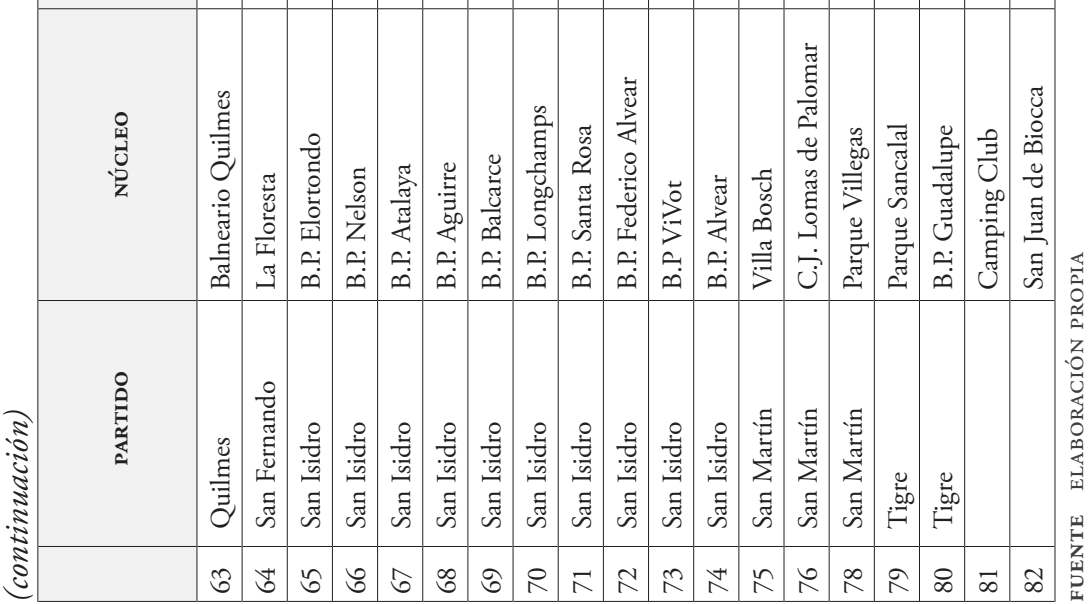




\section{Referencias bibliográficas}

Ballent, A. (1998). Country Life: los nuevos paraísos, su historia y sus profetas. Block (2), 88101.

Ballent, A. (2004). chalé (chalet). En J. Liernur \& F. Aliata (Dirs.), Diccionario de Arquitectura en la Argentina (pp. 67-69). Buenos Aires: Clarín.

Benévolo, A. (1993). La ciudad europea. Barcelona: Ediciones Crítica.

Bruno, P. (1997). Mar del Plata en los años 1930. El plan, ¿̨ausente? En C. Mazza (Ed.), La ciudad de papel. Análisis histórico de Normativas y Planes Urbanos para la ciudad de Mar del Plata, 1885-1975. Mar del Plata: Área Editorial.

Castells, M. (1973). Imperialismo y urbanización en América Latina. Barcelona: Gustavo Gili.

Chiozza, E. (1983). La integración del Gran Buenos Aires. En J. L. Romero \& L. A. Romero (Dirs.), Buenos Aires, historia de cuatro siglos (pp. 421-449). Buenos Aires: Editorial Abril.

Clichevsky, N. (1975). El mercado de tierras en el área de la expansión de Buenos Aires y su incidencia en los sectores populares, periodo 1943-1973. Buenos Aires: Centro de Estudios Urbanos y Regionales/Instituto Torcuato Di Tella.

Germani, G. (1942). La clase media en la ciudad de Buenos Aires: Estudio preliminar. Boletín del Instituto de Sociología (1), 105-126. Facultad de Filosofía y Letras, Universidad de Buenos Aires. Reproducido en Desarrollo Económico, 21(81), 109-127 (1981). En http://www.jstor.org/stable/3466371

Gómez Pintus, A. (2010). Suburbios residenciales. Modernización territorial, operaciones inmobiliarias e imágenes suburbanas, 1910-1940. Revista Iberoamericana de Urbanismo (5). En http://www.riurb.com/n5/05_02_AnaGomezPintus.pdf

Losada, L. (2008). La alta sociedad en la Buenos Aires de la Belle Époque. Buenos Aires: Siglo xxi.

Morse, R. (1969). Urbanization in Latin America. Latin American Review (Otońo).

Mumford, L. (1961). The city in history: Its origins, its transformations, and its prospects. Nueva York: Harcourt, Brace and World.

Randle, P. H. (1987). Geografía histórica argentina. Buenos Aires: Asociación para la promoción de Sistemas educativos no convencionales.

Romero, J. L. (1976). Latinoamérica: las ciudades y las ideas. Buenos Aires: Siglo XxI.

Sargent, Ch. (1974). The spatial evolution of Greater Buenos Aires. 1870-1930. Tesis presentada al Center for Latin American Studies, Arizona State University, Tempe, Arizona.

Schteingart, M. \& Torres, H. (1973). Procesos sociales y estructuración metropolitana en América Latina. Estudios de casos. Desarrollo Económico, 12(48), 725-760.

Svampa, M. (2001). Los que ganaron. La vida en countries y barrios cerrados. Buenos Aires: Editorial Biblos.

Szajnberg, D. (2001). La producción del espacio residencial en la Región Metropolitana de Buenos Aires. El caso de los barrios privados en Pilar y Berazategui. Actas del Seminario de Investigación Urbana. El nuevo milenio y lo urbano. Instituto e Investigaciones Gino Germani, Universidad de Buenos Aires (UBA); Instituto de Geografía, Facultad de Filosofía y Letras, uвA; Centro de Estudios Urbanos, ubA; Instituto del Conurbano, Universidad Nacional de General Sarmiento (UNGs).

Torres, H. (1975). Evolución de los procesos de estructuración espacial urbana. El caso de Buenos Aires. Desarrollo Económico, 15(58), 281-306. 
Torres, H. (1978). El mapa social de Buenos Aires en 1943, 1947 y 1960. Buenos Aires y los modelos urbanos. Desarrollo Económico, 18(70), 163-204.

Vapñarsky, C. (2000). La aglomeración Gran Buenos Aires. Expansión espacial y crecimiento demográfico entre 1869 y 1991. Buenos Aires: Eudeba.

Vidal-Koppmann, S. (2000). Las urbanizaciones privadas: ¿una innovación para la transformación del territorio? Scripta Nova, 4(69). En http://dialnet.unirioja.es/ servlet/oaiart? codigo $=249647$ 
